\title{
Microglial P2Y12 Receptor Regulates Seizure-Induced Neurogenesis and Immature Neuronal Projections
}

\author{
Mingshu Mo, ${ }^{1,2 *}$ U Ukpong B. Eyo, ${ }^{2,3,4 *}$ Manling Xie, ${ }^{3}$-Jiyun Peng, ${ }^{2,3}$ Dale B. Bosco, ${ }^{3}$ Anthony D. Umpierre, ${ }^{3}$ \\ Xiaoqin Zhu, ${ }^{1}$ Dai-Shi Tian, ${ }^{5}$ Pingyi $\mathrm{Xu},{ }^{1}$ and ${ }^{\circ}$ Long-Jun $\mathrm{Wu}^{2,3,6,7}$ \\ ${ }^{1}$ Department of Neurology, First Affiliated Hospital of Guangzhou Medical University, Guangzhou 510120, China, ${ }^{2}$ Department of Cell Biology and \\ Neuroscience, Rutgers University, Piscataway, New Jersey 08854, ${ }^{3}$ Department of Neurology, Mayo Clinic, Rochester, Minnesota 55905, ${ }^{4}$ Center for Brain \\ Immunology and Glia, Department of Neuroscience, University of Virginia, Charlottesville, Virginia 22908, ${ }^{5}$ Department of Neurology, Tongji Hospital, \\ Tongji Medical College, Huazhong University of Science and Technology, Wuhan, 430030, China, ${ }^{6}$ Department of Neuroscience, Mayo Clinic, Jacksonville, \\ Florida 32224, and 'Department of Immunology, Mayo Clinic, Rochester, Minnesota 55905
}

Seizures are common in humans with various etiologies ranging from congenital aberrations to acute injuries that alter the normal balance of brain excitation and inhibition. A notable consequence of seizures is the induction of aberrant neurogenesis and increased immature neuronal projections. However, regulatory mechanisms governing these features during epilepsy development are not fully understood. Recent studies show that microglia, the brain's resident immune cell, contribute to normal neurogenesis and regulate seizure phenotypes. However, the role of microglia in aberrant neurogenic seizure contexts has not been adequately investigated. To address this question, we coupled the intracerebroventricular kainic acid model with current pharmacogenetic approaches to eliminate microglia in male mice. We show that microglia promote seizure-induced neurogenesis and subsequent seizure-induced immature neuronal projections above and below the pyramidal neurons between the DG and the CA3 regions. Furthermore, we identify microglial $\mathrm{P} 2 \mathrm{Y} 12$ receptors $(\mathrm{P} 2 \mathrm{Y} 12 \mathrm{R})$ as a participant in this neurogenic process. Together, our results implicate microglial P2Y12R signaling in epileptogenesis and provide further evidence for targeting microglia in general and microglial P2Y12R in specific to ameliorate proepileptogenic processes.

Key words: immature projections; microglia; neurogenesis; P2Y12R; seizures

\section{Significance Statement}

Epileptogenesis is a process by which the brain develops epilepsy. Several processes have been identified that confer the brain with such epileptic characteristics, including aberrant neurogenesis and increased immature neuronal projections. Understanding the mechanisms that promote such changes is critical in developing therapies to adequately restrain epileptogenesis. We investigated the role of purinergic P2Y12 receptors selectively expressed by microglia, the resident brain immune cells. We report, for the first time, that microglia in general and microglial P2Y12 receptors in specific promote both aberrant neurogenesis and increased immature neuronal projections. These results indicate that microglia enhance epileptogenesis by promoting these processes and suggest that targeting this immune axis could be a novel therapeutic strategy in the clinic.

\section{Introduction}

Epilepsy is a common neurological disorder affecting millions of people worldwide. A common hallmark of the disorder is the

Received March 3, 2019; revised 0ct. 1, 2019; accepted 0ct. 2, 2019.

Author contributions: M.M., U.B.E., D.-S.T., P.X., and L.-J.W. designed research; M.M., U.B.E., M.X., J.P., D.B.B., and A.D.U. performed research; M.M., U.B.E., M.X., and L.-J.W. analyzed data; M.M., U.B.E., M.X., D.B.B., A.D.U., X.Z., D.-S.T., P.X., and L.-J.W. edited the paper; U.B.E. and L.-J.W. wrote the first draft of the paper; U.B.E. and L.-J.W. wrote the paper.

This work was supported by National Key R\&D Program of China Research Grants 2016YFC1306601 and 2017YFC1306002, National Natural Science Foundation of China Grants 81430021, 81870992, 81870856, 8177051165, U1503222, U1603281, and 81701254, Guangzhou Technology Projects 201504281820463 and 2018- occurrence of unprovoked seizures that results from an imbalance in brain excitation and inhibition. The most common form of epilepsy is mesial temporal lobe epilepsy (mTLE), which often remains intractable to pharmacological treatment, raising the
1202-SF-0019, Nature Science Foundation of Guangdong Province Grant 2018A030313649, and National Institutes of Health Grants R01NS088627, R21DE025689, R01NS112144, F32NS114040, and K22NS104392.

The authors declare no competing financial interests.

Correspondence should be addressed to Pingyi Xu at pingyixu@sina.com or Long-Jun Wu at wu.longjun@mayo.edu.

*M.M. and U.B.E. contributed equally to this work.

https://doi.org/10.1523/JNEUROSCI.0487-19.2019

Copyright $\odot 2019$ the authors 
need to further understand the underlying mechanisms that give rise to the pathology.

In mTLE, neurogenesis in the dentate gyrus (DG) is increased in both human patents and experimental models. Additionally, the epileptic environment promotes the sprouting of DG neurons toward the CA3 region along the mossy fiber pathway (Bausch and McNamara, 2004; Häussler et al., 2016; Godale and Danzer, 2018). The emerging consensus suggests that increased neurogenesis and neuronal sprouting are proepileptogenic (Cho et al., 2015; Hosford et al., 2016; Danzer, 2018). Therefore, reducing epileptic neurogenesis and excessive projections could serve as a therapeutic approach to limit the occurrence of seizures and progression of epilepsy. Along these lines, understanding the factors that regulate epileptic neurogenesis and DG sprouting offers an exciting avenue for research and potential therapeutic intervention.

Microglia, the brain's resident immune cells, have emerged as important players in neural development, nervous system homeostasis, and both acute and chronic brain pathologies (Eyo and Wu, 2013; Nayak et al., 2014; Salter and Beggs, 2014; Hammond et al., 2018). In the context of seizures and epilepsy, microglial research has lagged behind other acute pathologies, such as stroke and traumatic brain injury (Karve et al., 2016; Ma et al., 2017; Younger et al., 2019), as well as chronic diseases, such as pain and Alzheimer's disease (Beggs and Salter, 2013; Eyo et al., 2017a; Sarlus and Heneka, 2017). However, because inflammatory mechanisms have recently been implicated in the pathogenesis of epilepsy (Devinsky et al., 2013; Vezzani, 2014), the role of microglia is receiving increased interest. Research into microglia has been principally focused on acute seizures (Avignone et al., 2008; Mirrione et al., 2010; Eyo et al., 2014, 2017b), with the majority consensus being that microglia are beneficial (Eyo et al., 2017a; Waltl et al., 2018). However, in patients, spontaneous recurring seizures usually follow a latent period after the initial injury. In experimental studies, epilepsy development is often modeled by treatment with an excitotoxic agent, such as kainic acid (KA) or pilocarpine (Lévesque et al., 2016). Given the importance of aberrant neurogenesis and sprouting in epileptogenesis, understanding microglial contributions to these processes could provide an alternative strategy to limit epileptogenesis.

The p2ry12 gene that encodes the $\mathrm{P} 2 \mathrm{Y} 12$ receptor ( $\mathrm{P} 2 \mathrm{Y} 12 \mathrm{R})$ has emerged as one of the signature genes of microglia (Hickman et al., 2013; Butovsky et al., 2014; Bennett et al., 2016; Cronk et al., 2018). P2Y12R play important roles in basal microglial migration (Eyo et al., 2018), microglial physical interactions with neurons (Eyo et al., 2014, 2015, 2017b), and injury detection by microglia (Haynes et al., 2006). In pathology, they play various roles in ischemia (Webster et al., 2013) and pain (Tozaki-Saitoh et al., 2008; Gu et al., 2016a). We recently showed that, in the context of status epilepticus, P2Y12R-deficient mice have exacerbated behavioral seizures (Eyo et al., 2014). In the current study, we investigate the contributions of microglia in general and the microglial P2Y12R in specific on the latter effects of KA-induced seizures that are important for epileptogenesis. We report, for the first time, that pharmacogenetic elimination of microglia reduced both aberrant neurogenesis and seizure-induced immature neuronal projections. Furthermore, using genetic approaches, we show that $\mathrm{P} 2 \mathrm{Y} 12 \mathrm{R}$ contribute to these features of the epileptogenic environment. Our findings therefore highlight microglia and microglial-specific P2Y12R as potential targets in modulating epileptic phenotypes that could potentially be harnessed for the development of therapy against epileptogenesis.

\section{Materials and Methods}

Animals. Eight- to 10-week-old male mice were used in accordance with institutional guidelines approved by the animal care and use committee at the First Affiliated Hospital of Guangzhou Medical University, Rutgers University, and the Mayo Clinic. C57BL/6J and CX3CR1-GFP ${ }^{+/-}$mice (Jung et al., 2000) were purchased from The Jackson Laboratory. $\mathrm{P} 2 \mathrm{Y} 12 \mathrm{Rfl} / \mathrm{fl}$ mice were generated using a CRISPR/Cas9 system by Biocytogen (Peng et al., 2019). Briefly, the Cas9/guide RNA (gRNA) target sequences were designed to the regions upstream of exon 4 and downstream of $3^{\prime}$ UTR. The targeting construct consisting of $1 \mathrm{~kb}$ arms of homologous genomic sequence immediately upstream $\left(5^{\prime}\right)$ of exon 4 and downstream (3') of $3^{\prime}$ UTR flanked by two loxP sites. Cas9 mRNA and sgRNAs were transcribed with T7 RNA polymerase in vitro. Cas9 mRNA, sgRNAs, and donor vector were mixed at different concentrations and coinjected into the cytoplasm of fertilized eggs at the one-cell stage. Obtained F0 mice were validated by PCR amplification, direct sequencing, and Southern blot analysis. CX3CR1 ${ }^{\mathrm{CreER}}$ mice, donated by Dr. WenBiao Gan at New York University, were crossed with R2 $6^{\text {iDTR }}$ (purchased from The Jackson Laboratory) mice to generate CX3CR1 $\mathrm{CreER} /+$ : $\mathrm{R} 26^{\mathrm{iDTR} /+}$ mice for $\mathrm{CX} 3 \mathrm{CR} 1{ }^{+}$cell ablation or crossed with P2Y12Rfl/fl mice to provide CX3CR1 $1^{\text {CreER/+: }} \mathrm{P} 2 \mathrm{Y} 12 \mathrm{R}^{\mathrm{fl} / \mathrm{fl}}$ mice for the conditional $\mathrm{KO}$ of P2Y12R. P2Y12R general KO mice were donated by Dr. Michael Dailey at the University of Iowa. Mice were randomly distributed to experimental and control groups within a litter.

Microglial ablation and conditional KO of P2Y12R. Tamoxifen (SigmaAldrich), diluted in corn oil (Sigma-Aldrich) as $20 \mathrm{mg} / \mathrm{ml}$, was delivered to adult mice by intraperitoneal injection. For microglial ablation, four doses of tamoxifen $(150 \mathrm{mg} / \mathrm{kg})$ were given at $48 \mathrm{~h}$ intervals to induce the expression of DTR in CX3CR1-expressing cells in CX3CR1 ${ }^{\text {CreER }}$ : R2 ${ }^{\text {iDTR }}$ mice. Three weeks after the last tamoxifen treatment, diphtheria toxin (DT; Sigma-Aldrich, catalog \#D0564, $50 \mu \mathrm{g} / \mathrm{kg}, 2.5 \mu \mathrm{g} / \mathrm{ml}$ in PBS) was administered twice (at $2 \mathrm{~h}$ and $2 \mathrm{~d}$ after KA treatment) to ablate CX3CR1 resident myeloid cells, including microglia in the brain. Three weeks was required to allow for the turnover of CX3CR1 circulating monocytes and to avoid their ablation (Parkhurst et al., 2013; Peng et al., 2016). Mice treated with DT, but without tamoxifen, were used as controls. For conditional P2Y12R KO, four doses of tamoxifen $(75 \mathrm{mg} / \mathrm{kg})$ was given at $48 \mathrm{~h}$ intervals, whereas control mice were treated with corn oil only.

Epilepsy model. KA was delivered at $0.032 \mathrm{mg} / \mathrm{ml}$ in $5 \mu \mathrm{l}$ of ACSF in WT mice by intracerebroventricular injection. Given the increased susceptibility of mice lacking microglia and $\mathrm{P} 2 \mathrm{Y} 12$ receptors to seizures, mice with microglia ablation and lacking P2Y12 receptors were given $4.5 \mu \mathrm{l}$ drug to increase the survival rate. The coordinates were as follows: 0.2 $\mathrm{mm}$ caudal to bregma, $0.09 \mathrm{~mm}$ lateral to the midline, and $2.0-2.5 \mathrm{~mm}$ below the dura, depending upon the weight of mice. Seizure scores were evaluated for $2 \mathrm{~h}$ following KA treatment using the modified Racine scale: 1 , freezing behavior; 2 , rigid posture with raised tail; 3 , continuous head bobbing and forepaws shaking; 4 , rearing, falling, and jumping; 5 , continuous level $4 ; 6$, loss of posture and generalized convulsion activity; and 7, death (Racine, 1972; Avignone et al., 2008). Mice that progressed to at least Stage 3 were killed for immunohistochemistry at various time points.

Tissue staining and immunohistochemistry. After mice were deeply anesthetized by isoflurane $\left(5 \%\right.$ in $\left.\mathrm{O}_{2}\right)$, they were transcardially perfused with $20 \mathrm{ml}$ PBS followed by $20 \mathrm{ml}$ cold $4 \%$ PFA. The brain was removed and postfixed in $4 \%$ PFA for an additional $4-6 \mathrm{~h}$, then transferred to $30 \%$ sucrose in PBS overnight. Finally, $14 \mu \mathrm{m}$ slices were then cut with a cryostat (Leica Microsystems).

For Fluoro-Jade B (FJB) staining, sample slices were incubated in a solution of $1 \%$ sodium hydroxide in $80 \%$ ethanol for $5 \mathrm{~min}$, then in $70 \%$ ethanol for $2 \mathrm{~min}$, rinsed in distilled water, and treated with $0.06 \%$ potassium permanganate for $10 \mathrm{~min}$. After a rinse with distilled water, the slices were stained with $0.01 \%$ FJB (Histo-Chem) in $0.1 \%$ acetic acid for $20 \mathrm{~min}$. Slices were washed in PBS for $5 \mathrm{~min}$ and air dried.

For immunohistochemistry, after blocking with $5 \%$ goat serum and $0.3 \%$ Triton X-100 (Sigma-Aldrich) in TBS buffer, the slices were incubated with primary antibody for mouse anti-doublecortin (DCX, 1:500, 
a

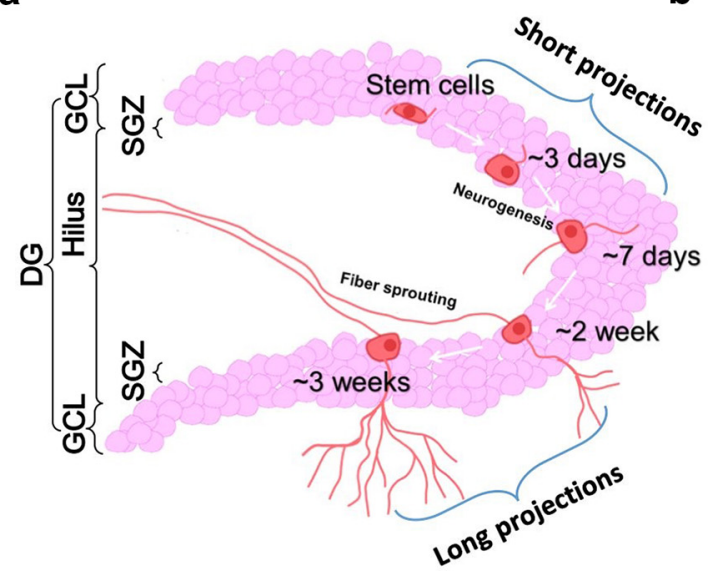

b

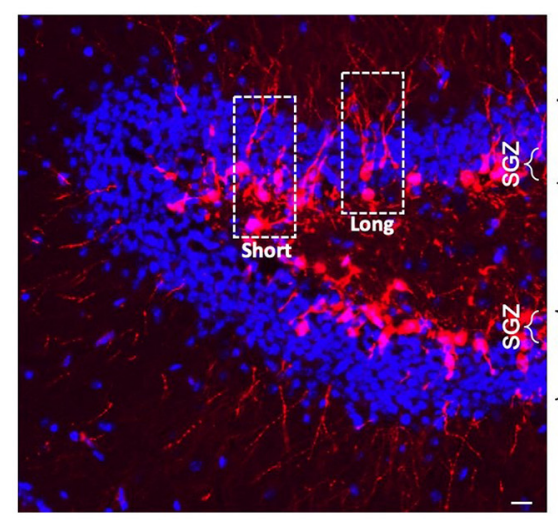

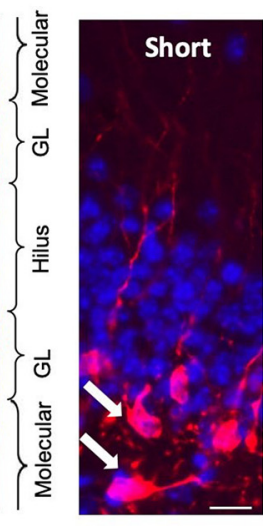

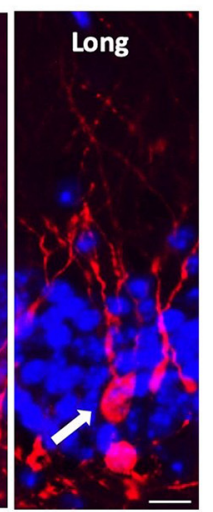

Figure 1. Short and long sprouts in the DG of KA-treated mice. $\boldsymbol{a}, \boldsymbol{b}$, Representative schematic ( $\boldsymbol{a}$ ) and immunofluorescent images ( $\boldsymbol{b}$ ) of short (arrowheads) and long sprouts (arrows) in the DG following intracerebroventricular KA treatment. Immature neurons with short and long neuronal projections were labeled with DCX (red) in conjunction with DAPI counterstaining (blue). Short sprouts remain within the DG cell body layer, whereas long sprouts extend beyond the DG cell body layer. Scale bar, $10 \mu \mathrm{m}$.

Sigma-Aldrich), rabbit anti-ki67(1:500, Abcam, catalog \#16667), and/or rabbit anti-Ibal (1:1000, Wako Chemicals, catalog \#019-19741) overnight at $4^{\circ} \mathrm{C}$. The slices were then incubated with secondary antibodies (1:500, AlexaFluor-594 and/or 1:500, AlexaFluor-488, Invitrogen) for 40 min at room temperature. After three washes with TBST, slices were mounted with DAPI fluoromount-GTM (Southern Biotechnology).

The immunofluorescent labeling technique was also used to stain BrdU-labeled cells following the reported procedure (Matsuda et al., 2015). Two hours after KA treatment, the mice were given BrdU (100 $\mathrm{mg} / \mathrm{kg}$ i.p., Sigma-Aldrich) once daily and killed $24 \mathrm{~h}$ after the last BrdU injection at 3 or $7 \mathrm{~d}$ after KA treatment. Tissue was processed and harvested as described above. The slices were incubated with $2 \times \mathrm{SSC} / 50 \%$ formamide for $2 \mathrm{~h}$ at $65^{\circ} \mathrm{C}, 2 \mathrm{~N} \mathrm{HCl}$ at $37^{\circ} \mathrm{C}$ for $1 \mathrm{~h}$, then $0.05 \mathrm{~m}$ borate buffer, $\mathrm{pH}$ 8.5, for $10 \mathrm{~min}$. After a PBS wash, slices were blocked in $10 \%$ BSA, and incubated with mouse anti-BrdU (1:500, Sigma-Aldrich) and mouse anti-DCX (1:500, Sigma-Aldrich) at $4^{\circ} \mathrm{C}$. After three PBS washes, sections were incubated with secondary antibodies (1:500, AlexaFluor594, and 1:500, AlexaFluor-488, Invitrogen) for $1 \mathrm{~h}$ at room temperature. After 3 washes with TBST, the slices were mounted with DAPI fluoromount-GTM.

Cell counts and image analysis. Fluorescent images were collected with a confocal microscope (LSM510, Carl Zeiss) or an optical microscope (EVOS FL Cell Imaging System, Invitrogen). Cell counting and fluorescent signal intensity were quantified using ImageJ software (National Institutes of Health, Bethesda, MD). We followed the procedure for cell counting in the DG as previously described (Matsuda et al., 2015). The total number of cells (only clear cell bodies were counted to avoid overestimation of cells) were assessed at every sixth section (14 $\mu \mathrm{m} / \mathrm{section})$ for 6 slices (i.e., $\sim 70 \mu \mathrm{m}$ intervals) in $\sim 500 \mu \mathrm{m}$ thickness. The cells labeled with DCX, Ki67, BrdU, or Iba1 in the DG were also counted. The number of counted cells in each section was summed, then multiplied by 6 to estimate the number of cells per DG. The DG volume was calculated as the product of the total area of sections by the thickness (Journiac et al., 2005) as follows: the sum of area measured was multiplied by the inverse of the sampling fraction of 6 and the section thickness of $14 \mu \mathrm{m}$. The density of cells per $\mathrm{mm}^{3}$ in DG was provided by the total number of labeled cells in the DG. This traditional method for accounting for density of cells per $\mathrm{mm}^{3}$ in the DG was used rather than stereological techniques, which is suitable for sections with thickness $>20 \mu \mathrm{m}$ (Wirenfeldt et al., 2003).

Cell projection image analysis. Fluorescent signals were detected by an optical microscope (EVOS FL Cell imaging System, Invitrogen) using a $40 \times$ objective. $\mathrm{DCX}^{+}$cells with long projections were classified as having lengths beyond the DG cell body region (Fig. 1a), suggestive of maturation beyond 2 weeks (Aimone et al., 2014). We measured the projections from DCX-labeled neurons and classified them as either long (extending beyond the DG cell body layer) or short (remaining within the DG cell body layer) (Fig. 1b). To quantify the density of either projection, we selected ROIs either of the region beyond the cell body layer (for long projections) or of the region identical to the cell body layer. For both, we quantified DCX florescence intensity in the total ROI. The $\mathrm{DCX}^{+}$projections outside the hilus were classified by their origin in either the suprapyramidal blade (SMF) or infrapyramidal blade (IMF). The size of SMF and IMF was determined through staining techniques, as has been previously reported (Römer et al., 2011). Briefly, in doublelabeled DAPI and DCX-labeled tissue, the maximum length of DCX projections above (for the SMF) or below (for the IMF) the DAPI ${ }^{+}$cell layer was quantified in ImageJ. Every sixth section in $500 \mu \mathrm{m}$ thickness was analyzed, and the average of the DCX pixel area was measured. The sum of areas measured was multiplied by the inverse of the sampling fraction with 6 and the section thickness with $14 \mu \mathrm{m}$ to calculate the volume of SMF or IMF projections.

Experimental design and statistical analyses. For all experiments, the number of mice for experiments is stated in the legends. Data are presented as mean \pm SEM. The Kolmogorov-Smirnov test was used to assess normality, and the Levene test was used to assess homoscedasticity. We confirmed that the histogram lay within normal distributions and the variance between groups was homogeneous. The significance was evaluated by Student's $t$ test, one-way ANOVA, and Wilcoxon rank-sum test ( $U$ test). The significance for two-group comparisons was evaluated using the Student's $t$ test. The comparison involving more than two groups was evaluated using multiple-way ANOVA, followed by Tukey post hoc test.

\section{Results}

To investigate the role of microglia in seizure-induced neurogenesis, we used the intracerebroventricular model of KA delivery to induce seizures. We first confirmed that neurons in the hippocampus show robust neurodegeneration following KA delivery. We observed an increase in FJB staining specifically in the CA3 region of the hippocampus at $3 \mathrm{~d}\left(F_{(3,44)}=67.09, p<\right.$ $0.001), 7 \mathrm{~d}\left(F_{(3,44)}=67.09, p<0.001\right)$, and $14 \mathrm{~d}\left(F_{(3,44)}=67.09\right.$, $p<0.001$ ) after the seizures (Fig. $2 a-c$ ). The DG region of the hippocampus does not display neurodegeneration in this model but exhibits robust neurogenesis in the steady state (Gonçalves et al., 2016; Anacker and Hen, 2017) and aberrant neurogenesis following seizures (Gray et al., 2002; Parent and Murphy, 2008). Therefore, we focused on this region to determine microglial contribution to seizure-induced aberrant neurogenesis and sprouting. 


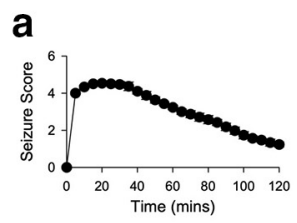

d Control

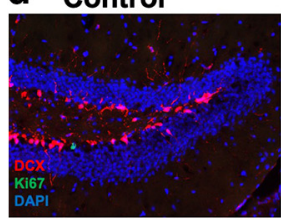

b

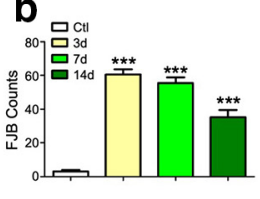

KA-3d

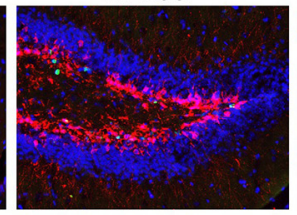

f

e

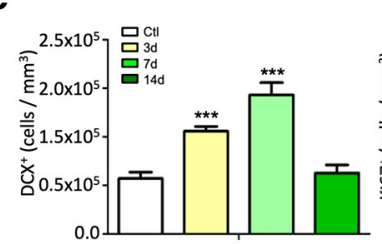

C

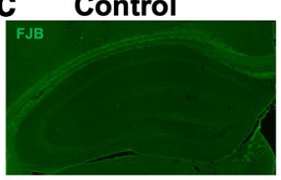

KA-7d

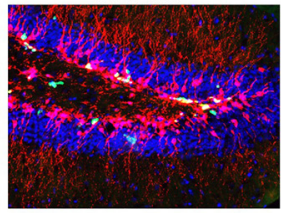

KA-3d

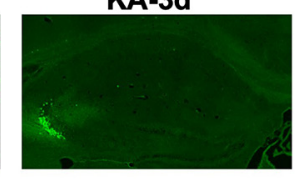

KA-7d

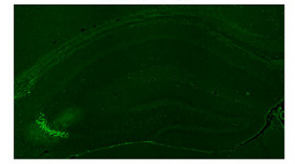

h

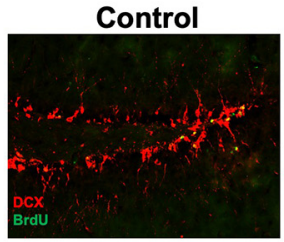

i

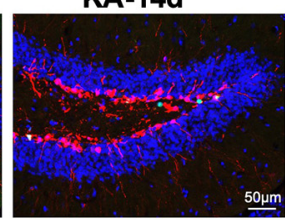

g

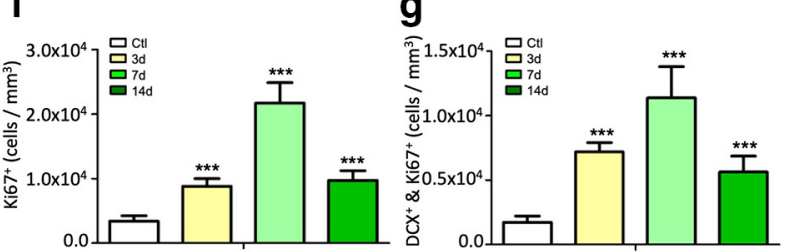

KA-14d

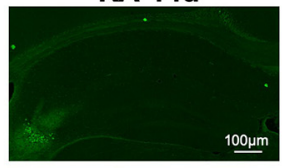

KA-7d

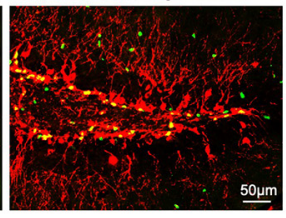

j

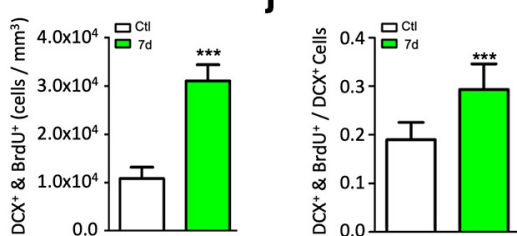

Figure 2. KA-induced seizures increase neurogenesis in the DG. $\boldsymbol{a}$, Seizure scores along a modified Racine scale for mice treated with KA through an intracerebroventricular injection ( $n=12)$. $\boldsymbol{b}$, c, Quantification of cells per section ( $\boldsymbol{b}$ ) and representative images (c) showing increased FJB expression in the hippocampus following intracerebroventricular KA seizures ( $n=7$ ). $\boldsymbol{d}$, Representative images of immature $\left(D C X^{+}\right)$and proliferating $\left(\mathrm{Ki} 7^{+}\right)$cells in the $\mathrm{DG}$ following intracerebroventricular KA seizures. $\boldsymbol{e}-\boldsymbol{g}$, Quantification of proliferating immature cells in the DG following seizures $(n=7)$. $\boldsymbol{h}$, Representative images of immature $\left(\mathrm{DCX}^{+}\right)$and proliferating $\left(\mathrm{BrdU}^{+}\right)$cells in the DG following intracerebroventricular KA seizures. ${ }^{* * *} p \leq 0.001$, compared with Control group $($ ANOVA with Tukey post hoc tests). $\boldsymbol{i}, \boldsymbol{j}$, Quantification of proliferating immature cells in the DG following seizures $(n=7) .{ }^{* * *} p \leq 0.001$ (Student's $t$ test).

\section{Experiment 1: seizures increase neurogenesis and neuronal projections}

Brains from control and KA-treated mice were stained at 3, 7, and $14 \mathrm{~d}$ postseizure induction with DCX, a marker of immature neurons, and Ki67, a marker of proliferating cells. We detected an increase in DCX- and Ki67-positive cells at day 3 (DCX: $F_{(3,24)}=$ 233.8, $p<0.001$; Ki67: $\left.F_{(3,24)}=80.52, p<0.001\right)$ that peaked at day 7 (DCX: $F_{(3,24)}=233.8, p<0.001 ; \operatorname{Ki} 67: F_{(3,24)}=80.52, p<$ $0.001)$ and declined by day 14 after KA (DCX: $F_{(3,24)}=233.8, p=$ 0.1102 ; Ki67: $F_{(3,24)}=80.52, p<0.001$ ) (Fig. $2 d-f$ ). The number of $\mathrm{DCX}^{+}: \mathrm{Ki} 7^{+}$double-positive cells (indicating proliferating immature neurons) similarly increased at day $3\left(F_{(3,24)}=12.12\right.$, $p<0.001)$, peaked at day $7\left(F_{(3,24)}=12.12, p<0.001\right)$, and declined by day $14\left(F_{(3,24)}=12.12, p<0.0235\right)$ after seizures (Fig. $2 g$ ). To complement these findings, we used a different proliferation marker, the thymidine analog, BrdU, which was injected daily beginning at $2 \mathrm{~h}$ after KA treatment for $7 \mathrm{~d}$ and the mice were killed $24 \mathrm{~h}$ after the final injection. We observed similar findings $7 \mathrm{~d}$ after KA, with an increase in $\mathrm{DCX}^{+}: \mathrm{BrdU}^{+}$cells $(\mathrm{df}=12, p<$ 0.001 ), representing $\sim 30 \%$ of the $\mathrm{DCX}^{+}$population $(\mathrm{df}=12, p<$ 0.001 ) (Fig. $2 h-j$ ). Thus, KA seizures significantly, though transiently, increases DG neurogenesis, as previously described in epileptogenesis (Parent et al., 1997; Parent, 2007; Jessberger and Parent, 2015).

In addition to neurogenesis, we also investigated seizureinduced increases in neuronal projections of immature neurons. During the maturation, $\mathrm{DCX}^{+}$DG neurons have both short projections and long projections characterized by projections beyond the DG granule cell body region (Aimone et al., 2014). An examination of apical projections revealed that both the long and short projections of DCX-labeled neurons increased by $3 \mathrm{~d}$ (long: $F_{(3,24)}=28.16, p<0.0001$; short: $\left.F_{(3,24)}=24.87, p=0.009\right)$, peaked at $7 \mathrm{~d}$ (long: $F_{(3,24)}=28.16, p<0.001$; short: $F_{(3,24)}=$ 24.87, $p<0.001$ ), and returned to control levels by $14 \mathrm{~d}$ (long: $F_{(3,24)}=28.16, p=0.2241$; short: $\left.F_{(3,24)}=24.87, p=0.5211\right)$ after seizures (Fig. $3 a-c$ ). Furthermore, projections of the mossy fiber pathway toward the CA3 region along both suprapyramidal and infrapyramidal pathways were examined. In response to seizures, immature $\mathrm{DCX}^{+}$neurons displayed increased volumes of these projections at $3 \mathrm{~d}$ (suprapyramidal: $F_{(3,24)}=6.493, p=$ 0.0311; infrapyramidal: $\left.F_{(3,24)}=15.65, p=0.0321\right)$ that peaked at $7 \mathrm{~d}$ (suprapyramidal: $F_{(3,24)}=6.493, p=0.0084$; infrapyramidal: $\left.F_{(3,24)}=15.65, p<0.001\right)$ and were normalized to control lengths by $14 \mathrm{~d}$ after seizures (suprapyramidal: $F_{(3,24)}=6.493$, $p=0.0784$; infrapyramidal: $F_{(3,24)}=15.65, p=0.1432$ ) (Fig. $3 d-f)$. Together, these results indicate that KA seizures transiently increase the projections of $\mathrm{DCX}^{+}$-immature neurons.

Experiment 2: microglia promote neurogenesis and immature neuronal projections after seizures

To investigate microglial involvement in neurogenesis and immature neuronal projections, we used the CX3CR $1^{\mathrm{GFP} /+}$ mouse line where microglia selectively express GFP (Jung et al., 2000). Microglial density in the DG increased significantly by $3 \mathrm{~d}\left(F_{(3,24)}\right.$ $=90.95, p<0.001)$ and was maintained through $14 \mathrm{~d}\left(F_{(3,24)}=\right.$ 90.95, $p<0.001$ ) of seizures (Fig. $4 a, b$ ), indicating that this model increases microglial numbers during the period of robust neurogenesis and immature neuronal projections.

To address a potential role for microglia in seizure-induced neurogenesis and increased projections, we used a genetic approach to eliminate microglia using CX3CR $1{ }^{\mathrm{CreER}}: \mathrm{R} 26^{\mathrm{iDTR}}$ mice, as we have done previously (Peng et al., 2016). Mice were treated with tamoxifen 4 times at $48 \mathrm{~h}$ intervals to express the DT receptor (DTR) in CX3CR1 cells. Three weeks after the last tamoxifen injection, mice were treated with KA to induce seizures. After seizures, mice were treated with DT twice (at $2 \mathrm{~h}$ and $2 \mathrm{~d}$ of KA treatment) to ablate CX3CR1-expressing cells. The 3 week period was required to allow for the turnover of circulating monocytes that also express CX3CR1 (Parkhurst et al., 2013). We confirmed that pretreatment of tamoxifen (for subsequent microglial ablation after KA) does not affect behavioral seizure severity (Fig. 4c). At $7 \mathrm{~d}$ after seizures, these microglia-ablated mice also exhibited 

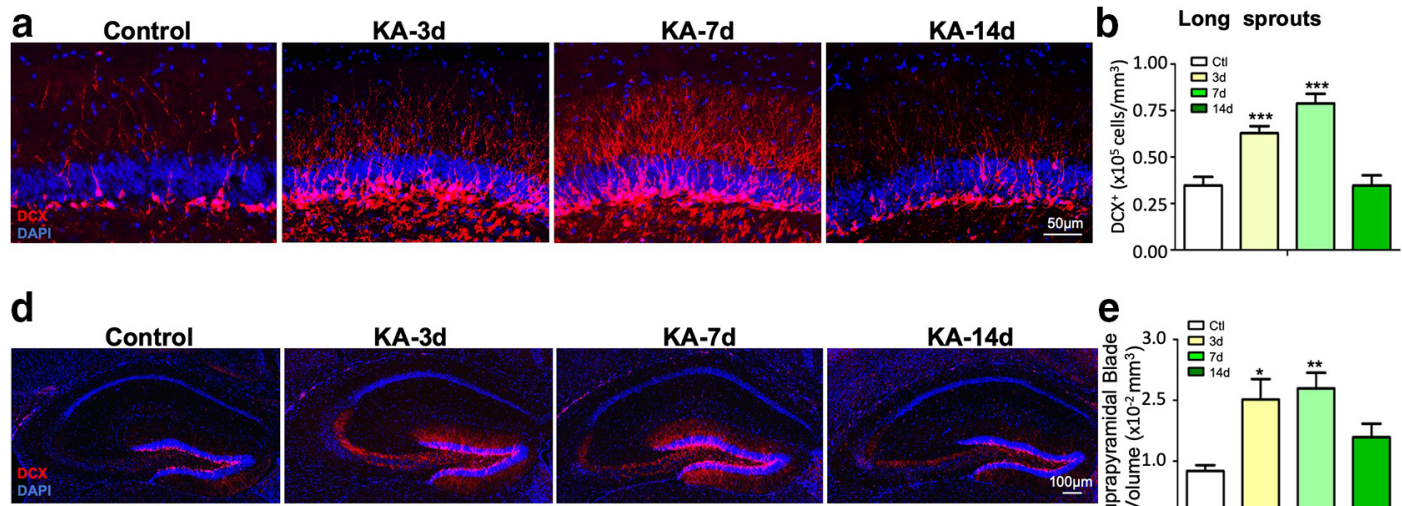

C Short sprouts
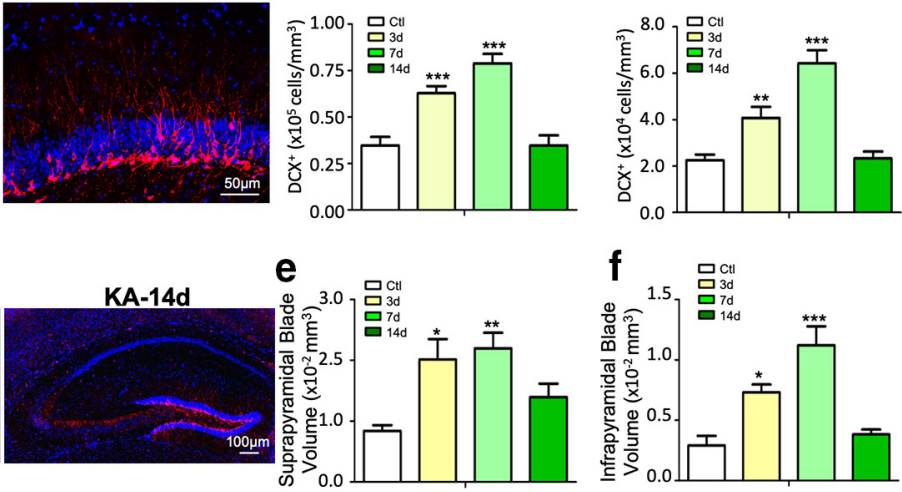

Figure 3. KA-induced seizures increase immature neuronal projections. $\boldsymbol{a}, \boldsymbol{c}$, Representative images of immature (DCX $\left.{ }^{+}\right)$cells ( $\left.\boldsymbol{a}\right)$ and quantification of long $(\boldsymbol{b})$ and short ( $\boldsymbol{c}$ ) projections showing increases following seizures in the DG $(n=7)$. $\boldsymbol{d}, \boldsymbol{f}$, Representative images of immature (DCX $\left.{ }^{+}\right)$cells $(\boldsymbol{d})$ and quantification of the suprapyramidal $(\boldsymbol{e})$ and infrapyramidal $(\boldsymbol{f})$ blade projections between the DG and the CA3 region of the hippocampus $(n=7)$. ${ }^{*} p \leq 0.05$, compared with Control group (ANOVA with Tukey post hoc tests). ${ }^{* *} p \leq 0.01$, compared with Control group (AN0VA with Tukey post hoc tests). ${ }^{* * *} p \leq 0.001$, compared with Control group (ANOVA with Tukey post hoc tests).

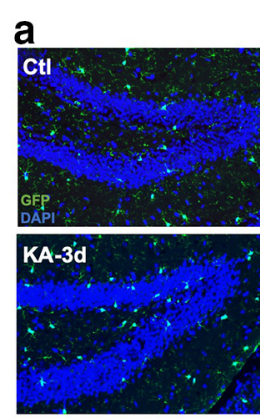

e

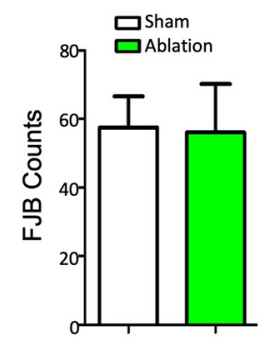

b

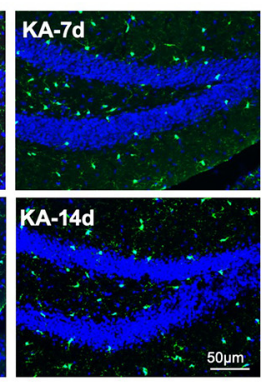

f Sham
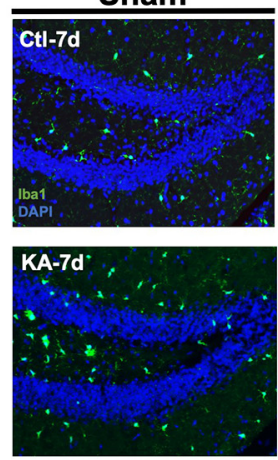

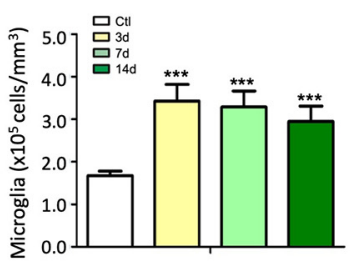

C
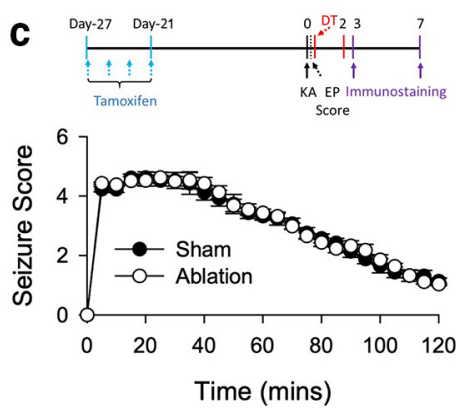

Time (mins)

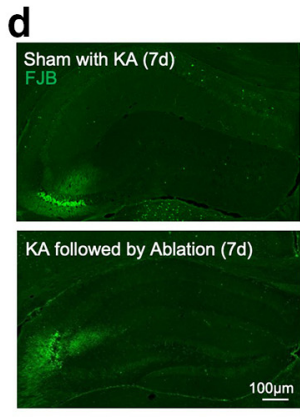

g
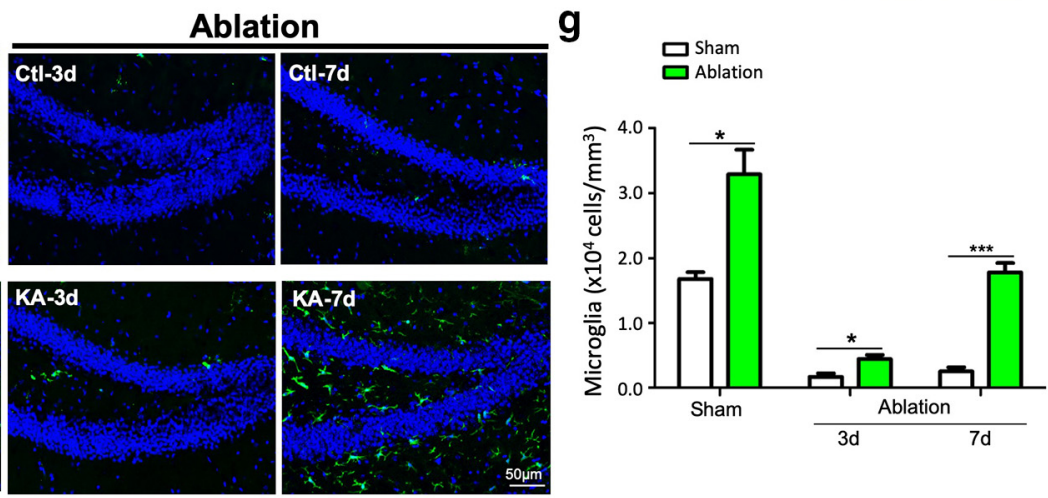

Figure 4. Microglial density after KA seizures and pharmacogenetic microglial ablation. $\boldsymbol{a}, \boldsymbol{b}$, Representative images from $\mathrm{CX3CR} 1^{\text {GFP/+ }}$ mice (a) and quantification of long projections (b) showing increased microglial density following seizures in the DG $(n=6) .{ }^{*} p \leq 0.05$, compared with Control group (ANOVA with Tukey post hoc tests). ${ }^{* * *} p \leq 0.001$, compared with Control group (ANOVA with Tukey post hoc tests).c, Top, Diagram of experimental procedures for ablation, seizures, and immunostaining. Bottom, Seizure scores along a modified Racine scale for sham or ablated mice treated with KA $(n=8)$. $\boldsymbol{d}$, $\boldsymbol{e}$, Representative images ( $\boldsymbol{d})$ and quantification (e) showing similar FJB expression in the hippocampus following intracerebroventricular KA seizures followed by sham treatment or microglial ablation (cells per section; $n=6$ ). ${ }^{*} p \leq 0.05$ (Student's ttest). $\boldsymbol{f}, \boldsymbol{g}$, Representative images $(\boldsymbol{f})$ and quantification $(\boldsymbol{g})$ of microglial density after KA treatment with sham or microglial ablation strategies at $3-7 \mathrm{~d}$ of KA treatment $(n=6) .{ }^{*} p \leq 0.05$ (two-factorial ANOVA with Bonferroni post hoc tests). ${ }^{* * *} p \leq 0.001$ (two-factorial ANOVA with Bonferroni post hoc tests).

similar FJB cell counts to sham-treated mice $(\mathrm{df}=6, p=0.9318)$ (Fig. $4 d, e)$ as well as similar pyknotic nuclei indicative of apoptotic cells (data not shown). This suggests that the degree of neurodegeneration is dependent on the degree of seizures induced by the initial KA treatment and is unaffected by a subsequent microglial ablation.

In control mice (no KA treatment), DT injection could significantly reduce microglial numbers $3 \mathrm{~d}\left(F_{(2,36)}=446.1, p=\right.$ $0.0328)$ and $7 \mathrm{~d}\left(F_{(2,36)}=446.1, p<0.001\right)$ after the first DT injection (Fig. $4 f$, top, $g$, white bars). However, the same proce- dure in KA-treated mice resulted in elevated microglial numbers at 3 and $7 \mathrm{~d}$ after the first DT injection compared with saline controls (Fig. $4 f$, bottom, $g$, light green bars). Thus, the postseizure environment may be able to stimulate the faster repopulation of microglia than control conditions following pharmacogenetic ablation.

After determining that microglial ablation does not affect neurodegeneration, we next investigated the consequence of ablation on neurogenesis and neuronal sprouting in control (saline) and KA epileptogenesis conditions. By $7 \mathrm{~d}$ (but not by $3 \mathrm{~d}$ ) of 


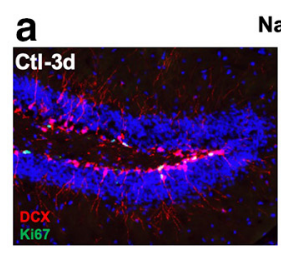

Naive
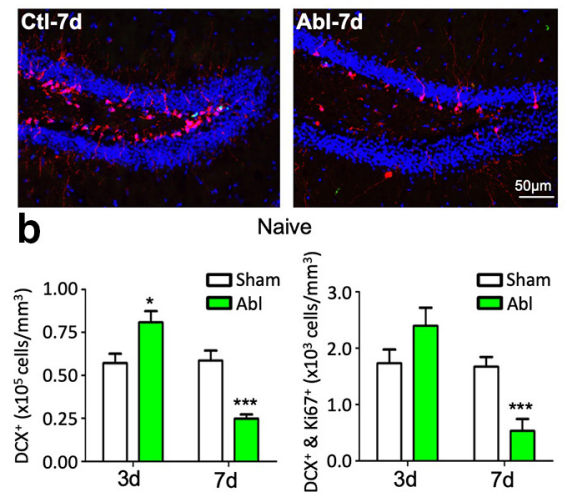

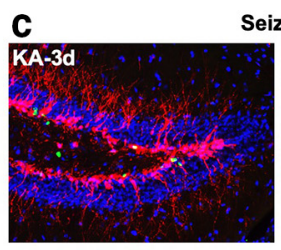

Seizures
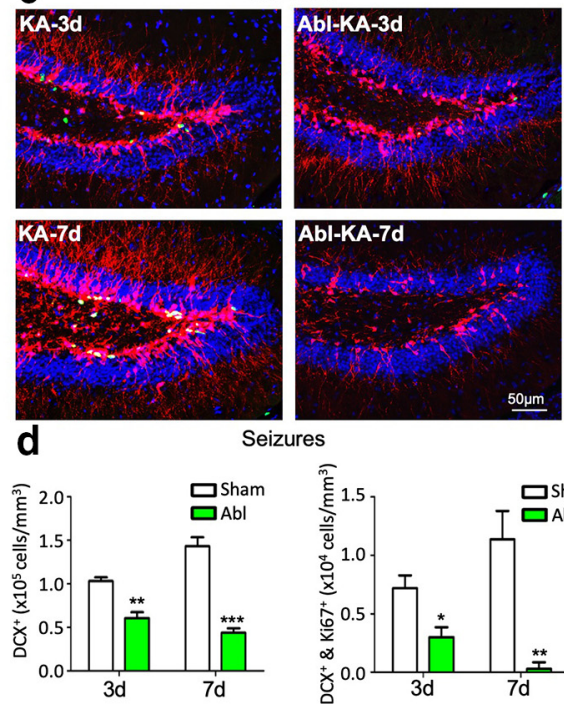

e
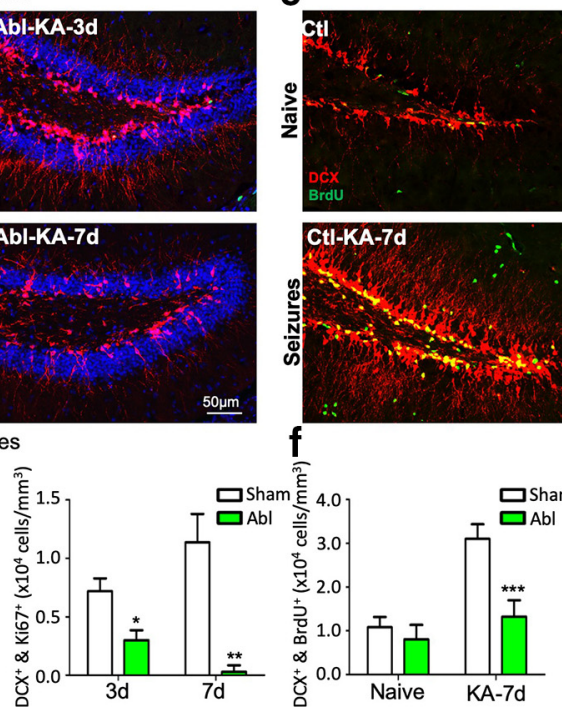
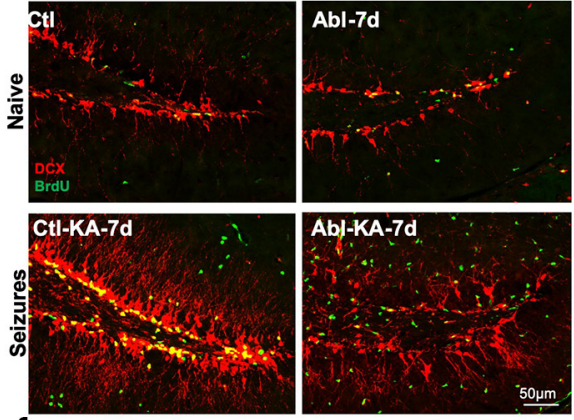

$f$
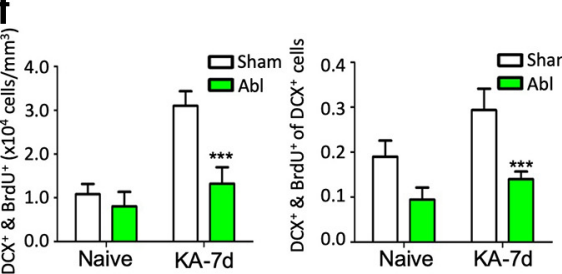

Figure 5. Microglial ablation reduces seizure-induced neurogenesis. $\boldsymbol{a}, \boldsymbol{b}$, Representative images $(\boldsymbol{a})$ and quantification $(\boldsymbol{b})$ of immature $\left(D C X^{+}\right)$and proliferating (Ki67 $\left.{ }^{+}\right)$cells in the DG following sham treatment and microglial ablation in naive mice $(n=6) . \boldsymbol{c}, \boldsymbol{d}$, Representative images $(\boldsymbol{c})$ and quantification $(\boldsymbol{d})$ of immature $\left(D C X^{+}\right)$and proliferating $\left(\right.$Ki $\left.67^{+}\right)$cells in the $D G$ following sham treatment and microglial ablation in KA-treated mice $(n=6) \cdot \boldsymbol{e}, \boldsymbol{f}$, Representative images $(\boldsymbol{e})$ and quantification $(\boldsymbol{f})$ of immature $\left(\mathrm{DCX}{ }^{+}\right)$and proliferating $\left(\mathrm{BrdU}{ }^{+}\right)$cells in the $\mathrm{DG}$ following sham treatment and microglial ablation in naive and KA-treated mice $(n=6) .{ }^{*} p \leq 00.05$, compared with Sham group (two-factorial ANOVA with Bonferroni posthoc tests). ${ }^{* *} p \leq 0.01$, compared with Sham group (two-factorial ANOVA with Bonferroni post hoc tests). ${ }^{* * *} p \leq 0.001$, compared with Sham group (two-factorial ANOVA with Bonferroni post hoc tests).

microglial ablation in naive mice, neurogenesis, as detected by $\operatorname{DCX}\left(F_{(1,24)}=206.0, p<0.001\right)$ and $\operatorname{Ki67}\left(F_{(1,24)}=26.94, p<\right.$ $0.001)$, was significantly reduced compared with nonablated conditions (Fig. $5 a, b$ ), suggesting that microglia promote ongoing neurogenesis in the steady state. Following seizures at both $3 \mathrm{~d}$ $\left(\mathrm{DCX}^{+}: F_{(1,24)}=2.329, p=0.002 ; \mathrm{DCX}^{+}\right.$and $\mathrm{Ki}^{+}: F_{(1,24)}=$ $0.4448, p=0.031)$ and $7 \mathrm{~d}\left(\mathrm{DCX}^{+}: F_{(1,24)}=2.329, p<0.001\right.$; $\mathrm{DCX}^{+}$and $\left.\mathrm{Ki}^{+}: F_{(1,24)}=0.4448, p<0.001\right)$, microglial ablation also significantly reduced DG neurogenesis (Fig. $5 c, d$ ). This observation was further confirmed with BrdU as an alternative proliferation marker at $7 \mathrm{~d}$ (but not $3 \mathrm{~d}$ ) of seizures $\left(\mathrm{DCX}^{+}\right.$and $\operatorname{DrdU}^{+}: F_{(1,24)}=124.6, p<0.001 ; \mathrm{DCX}^{+}$and $\mathrm{DrdU}^{+} / \mathrm{DCX}^{+}$: $F_{(1,24)}=5.264, p<0.001$ ) (Fig. 5e,f). Together, these results indicate that microglia promote both basal and seizure-induced neurogenesis in the adult DG.

We also investigated the effect of microglial ablation on seizure-induced immature neuronal projections. In the naive state, microglial ablation for $7 \mathrm{~d}$ (but not $3 \mathrm{~d}$ ) resulted in a reduction in the degree of apical projections for both long $\left(F_{(3,48)}=\right.$ $67.88, p<0.001)$ and short $\left(F_{(3,48)}=67.88, p<0.001\right)$ dendrites (Fig. $6 a, b)$. Similarly, after seizures, at both $3 \mathrm{~d}$ (long: $F_{(3,48)}=$ 23.86, $p<0.001$; short: $F_{(3,48)}=23.86, p=0.008$ ) and $7 \mathrm{~d}$ (long: $F_{(3,48)}=23.86, p<0.001$; short: $\left.F_{(3,48)}=23.86, p<0.001\right)$, microglial ablation resulted in a significant reduction in the apical projections (Fig. $6 c, d$ ). In addition to apical projections of immature DCX-expressing neurons, we examined the influence of microglia on basal and seizure-induced projections from immature neurons along the mossy fiber pathway. Microglial ablation also reduced basal (infrapyramidal volume: $F_{(3,48)}=19.75$, $p=0.0324$; suprapyramidal volume: $\left.F_{(3,48)}=19.75, p<0.001\right)$ (Fig. 6e,f) and seizure-induced (Fig. $6 g, h$ ) (infrapyramidal volume: $F_{(3,48)}=27.93, p=0.008$; suprapyramidal volume: $F_{(3,48)}=$ 27.93, $p<0.001)$ infrapyramidal and suprapyramidal volumes. Together, these observations indicate that microglia promote the steady state and seizure-induced projection of immature neurons following seizures.
Experiment 3: P2Y12R regulate neurogenesis and immature neuronal projections after seizures

Next, we attempted to determine a molecular pathway by which microglia regulate seizure-induced neurogenesis. We turned our attention to P2Y12R that are highly and exclusively expressed by microglia in the homeostatic state (Hickman et al., 2013) and significantly upregulated following seizures (Avignone et al., 2008; Eyo et al., 2018). We confirmed our previous results (Eyo et al., 2014) that a global P2Y12R deficiency increased seizure severity $(\mathrm{df}=10, p=0.0005)$ and neurodegeneration $\left(F_{(1,24)}=505.4\right.$, $p<0.001$ ) (Fig. $7 a-c$ ) as well as cells with pyknotic nuclei (data not shown).

Next, we used P2Y12 $\mathrm{R}^{-1-}$ mice and examined basal and seizure-induced neurogenesis and immature neuronal projections. While basal neurogenesis in the DG was unaffected by a genetic P2Y12R deficiency, seizure-induced neurogenesis, as determined by $\operatorname{DCX}\left(F_{(1,24)}=65.11, p=0.004\right), \operatorname{Ki67}\left(F_{(1,24)}=\right.$ 29.39, $p=0.008)$, and $\operatorname{BrdU}\left(F_{(1,24)}=21.46, p<0.001\right)$ immunoreactivity, was significantly reduced (Fig. $7 d-h)$. Similarly, apical DG (Fig. $8 a-c$ ) (long: $F_{(1,24)}=21.46, p<0.001$; short: $F_{(1,24)}$ $=33.03, p<0.001)$ as well as infrapyramidal and suprapyramidal (Fig. $8 d-f$ ) (suprapyramidal volume: $F_{(1,24)}=90.19, p<$ 0.001 ; infrapyramidal volume: $\left.F_{(1,24)}=31.32, p=0.007\right)$ projections were unaltered in $\mathrm{P} 2 \mathrm{Y} 12 \mathrm{R}^{-1-}$ mice at baseline but were significantly reduced following seizures.

Although P2Y12R is exclusively expressed by microglia in the brain parenchyma, platelets that circulate in the blood also express this receptor (Andre et al., 2003) and could modulate neurogenic and projection phenotypes through their neurovascular interactions. In addition, deletion of P2Y12R could affect brain development since it is highly expressed during early development (Bennett et al., 2016; Hammond et al., 2019). To rule out platelet P2Y12R function or developmental complications as a contributor to the observed P2Y12R-dependent effects, we generated conditional $\mathrm{P} 2 \mathrm{Y} 12 \mathrm{R}^{\mathrm{fl} / \mathrm{fl}}$ mice (see Materials and Methods). Once crossed with the CX3CR1 ${ }^{\text {CreER }}$ mouse line, 

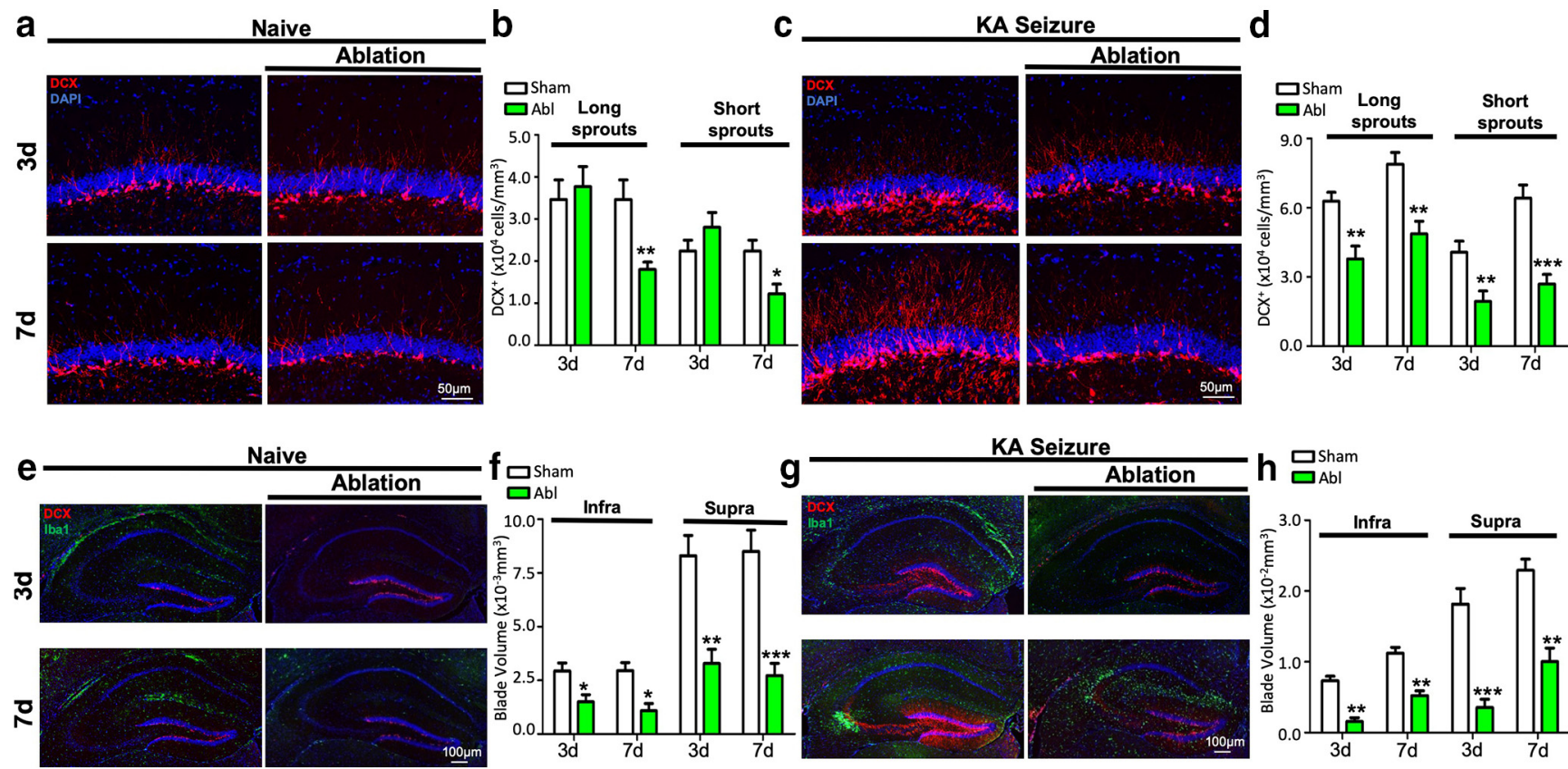

Figure 6. Microglial ablation reduces seizure-induced immature neuronal projections. $\boldsymbol{a}, \boldsymbol{b}$, Representative images $(\boldsymbol{a})$ and quantification $(\boldsymbol{b})$ of immature $\left(D C X^{+}\right)$cell sprouts in the $D G$ following sham treatment and microglial ablation in naive mice $(n=6) . \boldsymbol{c}, \boldsymbol{d}$, Representative images $(\boldsymbol{c})$ and quantification $(\boldsymbol{d})$ of immature $\left(D C X^{+}\right)$cell projections in the $D G$ following sham treatment and microglial ablation in KA-treated mice $(n=6) . e, f$, Representative images $(\boldsymbol{e})$ and quantification $(\boldsymbol{f})$ of immature $\left(D C X{ }^{+}\right)$and $\mathrm{lba} 1^{+}$cells and blade length in the $D G$ following sham treatment and microglial ablation in naive mice $(n=6) \cdot \boldsymbol{g}, \boldsymbol{h}$, Representative images $(\boldsymbol{g})$ and quantification $(\boldsymbol{h})$ of immature $\left(\mathrm{DCX}{ }^{+}\right)$and $\mathrm{lba}^{+}$cells and blade length in the $\mathrm{DG}$ following sham treatment and microglial ablation in KA-treated mice (per section; $n=6$ ). ${ }^{*} p \leq 0.05$, compared with Sham group (two-factorial ANOVA with Bonferroni post hoc tests). ${ }^{* *} p \leq 0.01$, compared with Sham group (two-factorial ANOVA with Bonferroni post hoc tests). ${ }^{* *} p \leq 0.001$, compared with Sham group (two-factorial ANOVA with Bonferroni post hoc tests).

a

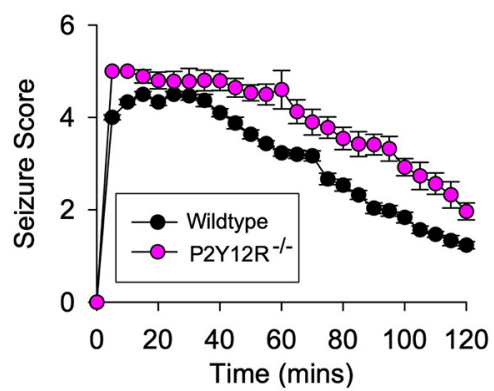

b

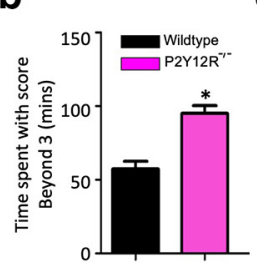

C

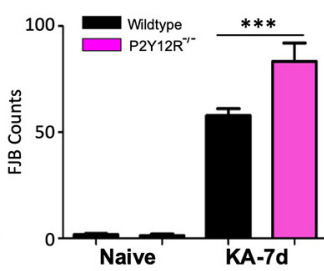

d

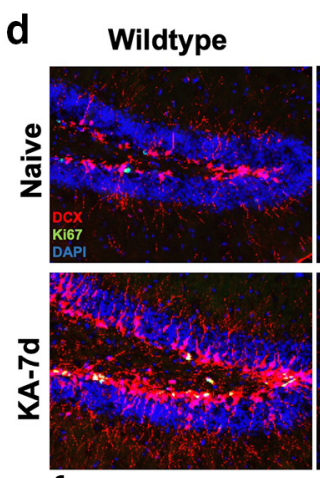

f

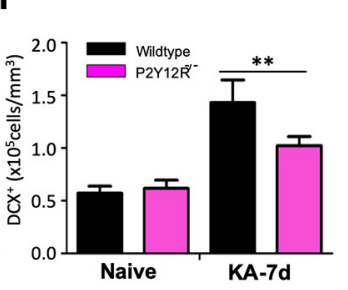

P2Y12R $^{-/-}$

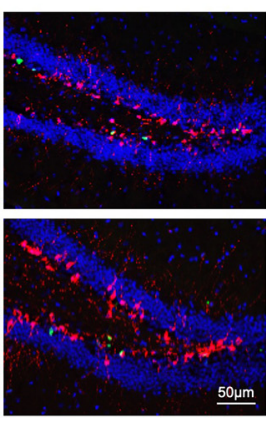

g

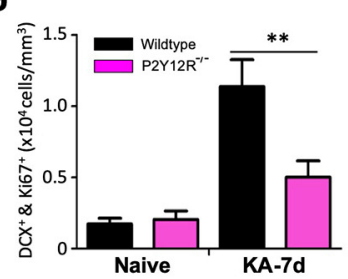

e Wildtype

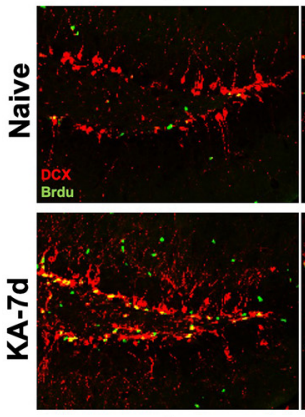

h

Figure 7. P2Y12R K0 mice show reduced seizure-induced neurogenesis. $\boldsymbol{a}$, Seizure scores along a modified Racine scale for aged-matched WT and P2Y12 ${ }^{-1-}$ mice treated with KA through an intracerebroventricular injection $(n=8), \boldsymbol{b}, \boldsymbol{c}$, Quantitation of $(\boldsymbol{b})$ time spent beyond Stage 3 seizures during KA treatment and $(\boldsymbol{c})$ FJB expression in the hippocampus following KA seizures ( $n=6$ ). $\boldsymbol{d}, \boldsymbol{e}$, Representative images of immature $\left(\mathrm{DCX}{ }^{+}\right)$and proliferating $\left(\boldsymbol{d}, \mathrm{Ki}^{+} 7^{+}\right.$or $\left.\boldsymbol{e}, \mathrm{BrdU}{ }^{+}\right)$cells in the DG in aged-matched naive and WT and P2Y12 ${ }^{-/-}$mice treated with KA. $\boldsymbol{f}-\boldsymbol{h}, \mathrm{Quantification}$ of $(\boldsymbol{f})$ immature $\left(D C X^{+}\right)$and proliferating $\left(\boldsymbol{g}, \mathrm{Ki}^{+} 7^{+}\right.$or $\left.\boldsymbol{h}, \mathrm{BrdU}{ }^{+}\right)$cells in the DG in aged-matched naive and WT and P2Y12 ${ }^{-1-}$ mice treated with KA $(n=6)$. ${ }^{*} p \leq 0.05$ (two-factorial ANOVA with Bonferroni post hoc tests). ${ }^{* *} p \leq 0.01$ (two-factorial ANOVA with Bonferroni post hoc tests). ${ }^{* *} p \leq 0.001$ (two-factorial ANOVA with Bonferroni post hoc tests).

and subsequently treated with tamoxifen, these adult mice exhibit selective depletion of microglial P2Y12R $\left(\mathrm{cP}^{\mathrm{Y}} 12 \mathrm{R}^{-1-}\right)$. In CP2Y12R $\mathrm{R}^{-1-}$ mice, seizure-induced neurogenesis $\left(\mathrm{DCX}^{+}\right.$and $\mathrm{Ki}^{+}: F_{(1,24)}=25.29, p<0.001 ; \mathrm{DCX}^{+}$and $\operatorname{DrdU}^{+}: F_{(1,24)}=$ 25.14, $p=0.004$ ) (Fig. $9 a-c$ ), apical DG (long: $F_{(1,24)}=35.48$, $p<0.001$; short: $\left.F_{(1,24)}=33.39, p<0.001\right)$ (Fig. $9 d-f$ ), as well as infrapyramidal and suprapyramidal projections (suprapyramidal volume: $F_{(1,24)}=48.21, p<0.001$; infrapyramidal volume: $F_{(1,24)}=18.05, p=0.007$ ) (Fig. $\left.9 g-i\right)$ were attenuated. Together, these results indicate that microglial-specific P2Y12R promote seizure-induced aberrant neurogenesis and immature neuronal projections. 
a
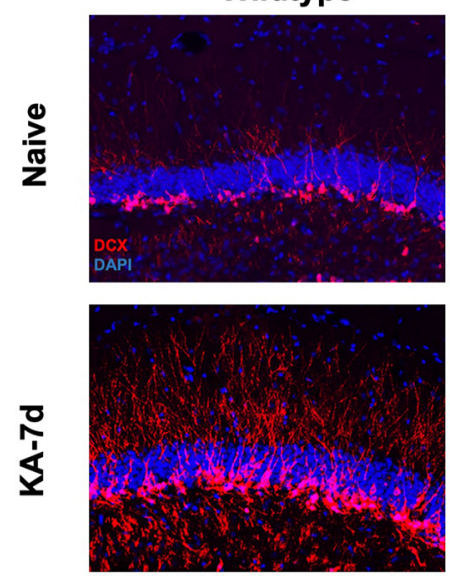

b

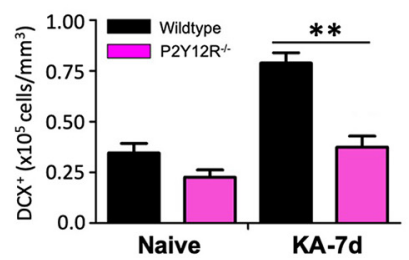

P2Y12R ${ }^{-I-}$
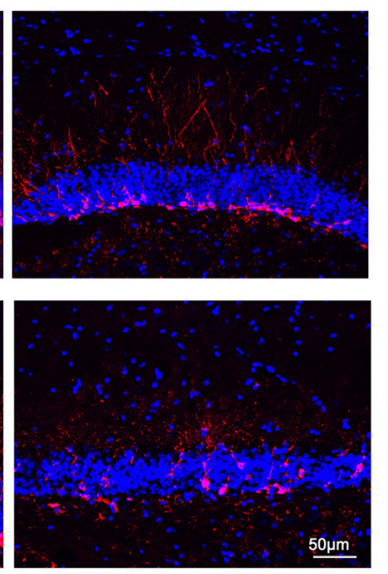

C

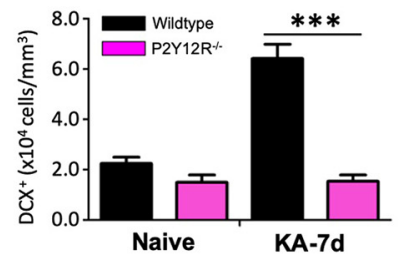

d
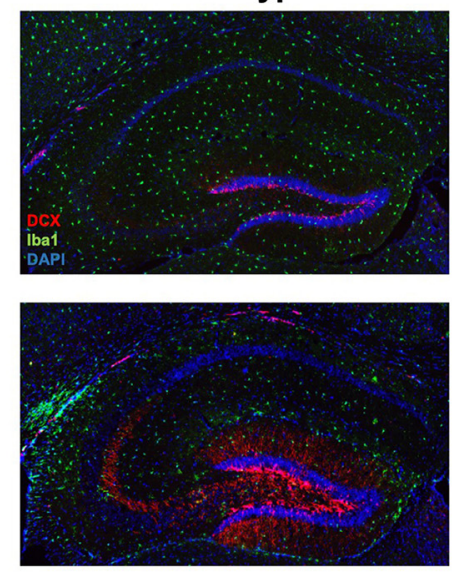

e

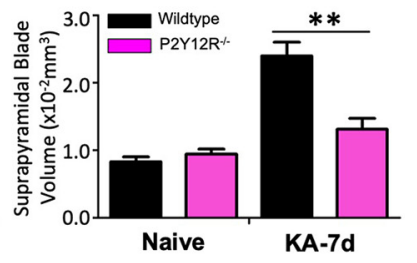

P2Y12R
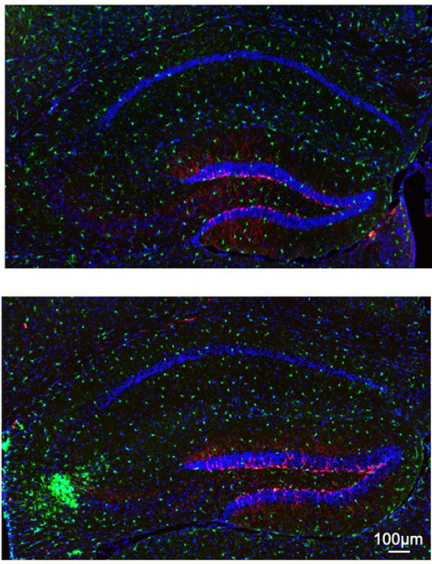

f

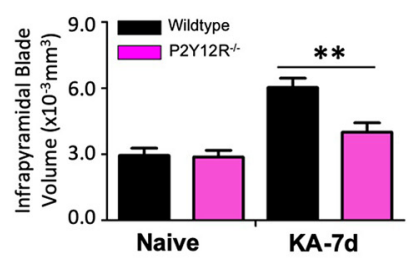

Figure 8. P2Y12R K0 mice show reduced seizure-induced immature neuronal projections. $\boldsymbol{a}-\boldsymbol{c}$, Representative images of immature $\left(D C X^{+}\right)$cells $(\boldsymbol{a})$ and quantification of long $(\boldsymbol{b})$ and short $(\boldsymbol{c})$ projections showing increases in aged-matched naive and WT and P2Y12 $2^{-\prime-}$ mice treated with KA $(n=6)$. $\boldsymbol{d}-\boldsymbol{f}$, Representative images of immature $\left(D C X^{+}\right)$cells $(\boldsymbol{d})$ and quantification of the suprapyramidal $(\boldsymbol{e})$ and infrapyramidal $(\boldsymbol{f})$ blade projections from the DG to the CA3 region of the hippocampus in aged-matched naive and WT and P2Y12 ${ }^{-1-}$ mice treated with KA $(n=6){ }^{* *} p \leq$ 0.01 (two-factorial ANOVA with Bonferroni post hoc tests). ${ }^{* * *} p \leq 0.001$ (two-factorial ANOVA with Bonferroni post hoc tests).

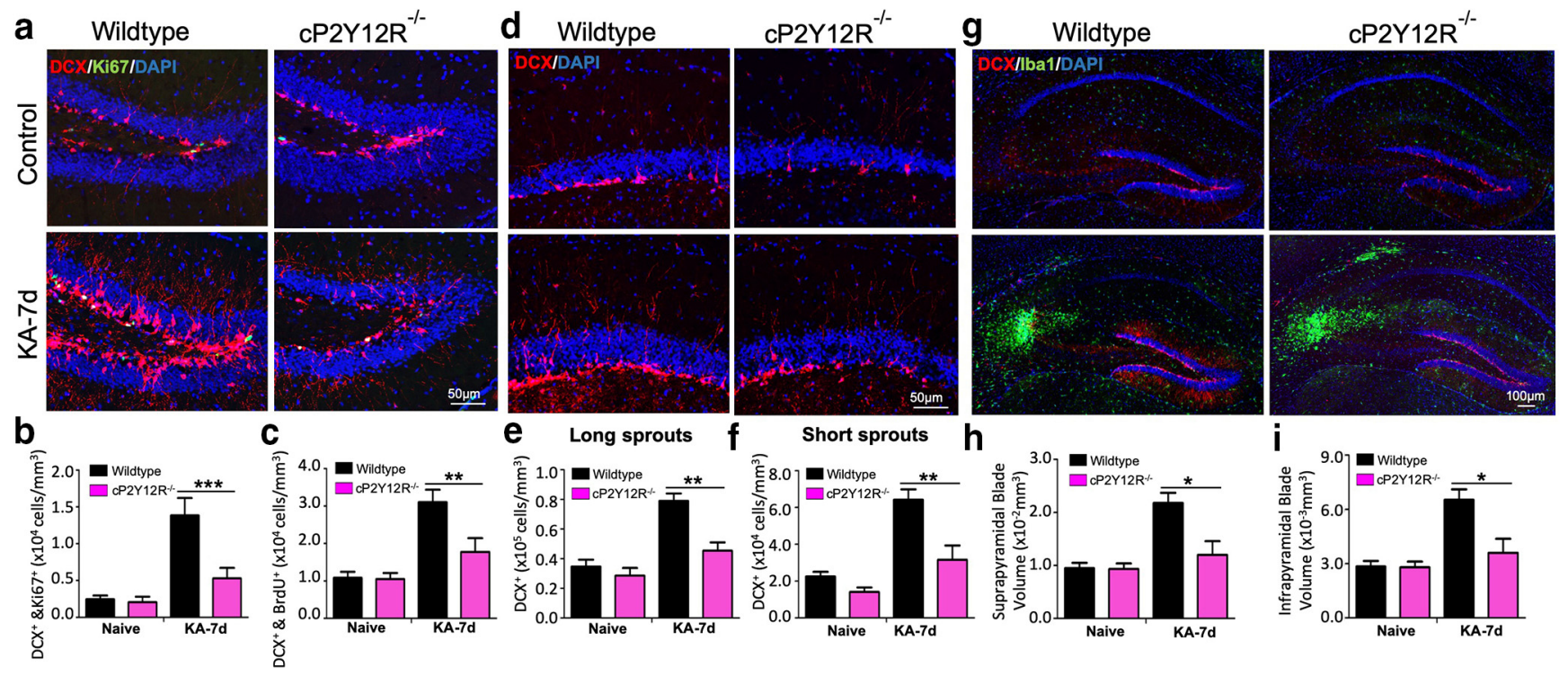

Figure 9. Conditional P2Y12R K0 mice show reduced seizure-induced neurogenesis and immature neuronal projections. $\boldsymbol{a}-\boldsymbol{c}$, Representative images $(\boldsymbol{a})$ of immature $\left(D C X^{+}\right)$and proliferating $\left(\boldsymbol{b}, \mathrm{Ki}^{6} 7^{+}\right.$or $\boldsymbol{c}$, BrdU $\left.{ }^{+}\right)$cells in the DG in aged-matched naive and KA-treated WT and conditional P2Y12 ${ }^{-1-}$ mice $(n=6) . \boldsymbol{d}-\boldsymbol{f}$, Representative images $(\boldsymbol{d})$ of immature $\left(D C X X^{+}\right)$showing long $(\boldsymbol{e})$ and short $(\boldsymbol{f})$ immature neuronal projections in aged-matched naive and KA-treated WT and conditional P2Y12 ${ }^{-1-}$ mice $(n=6) \cdot \boldsymbol{g}-\boldsymbol{i}$, Representative images $(\boldsymbol{g})$ of immature $(D C X+)$ showing lengths of suprapyramidal ( $\boldsymbol{h}$ ) and infrapyramidal (i) sprouts in aged-matched naive and KA-treated WT and conditional P2Y12 ${ }^{-1-}$ mice $(n=6)$. ${ }^{*} p \leq 0.05$ (two-factorial ANOVA with Bonferroni post hoc tests). ${ }^{* *} p \leq 0.01$ (two-factorial ANOVA with Bonferroni post hoc tests). ${ }^{* *} p \leq 0.001$ (two-factorial ANOVA with Bonferroni post hoc tests).

\section{Discussion}

In this study, we examined seizure-induced neurogenesis and neuronal sprouting in the hippocampal DG following intracerebroventricular KA treatment-induced seizures. Increased neurogenesis and immature neuronal projections were observed beginning at $3 \mathrm{~d}$, peaking at $7 \mathrm{~d}$. and returning to normal levels by
$14 \mathrm{~d}$ of KA treatment. This transient increase is consistent with the findings from a previous study in which mice were treated with KA via intrahippocampal injection. There, increased proliferation of neural crest cells was detected at 3 and $7 \mathrm{~d}$, but not $50 \mathrm{~d}$, following KA treatment (Sierra et al., 2015). Next, we coupled seizures with effective pharmacogenetic ablation of microglia in 


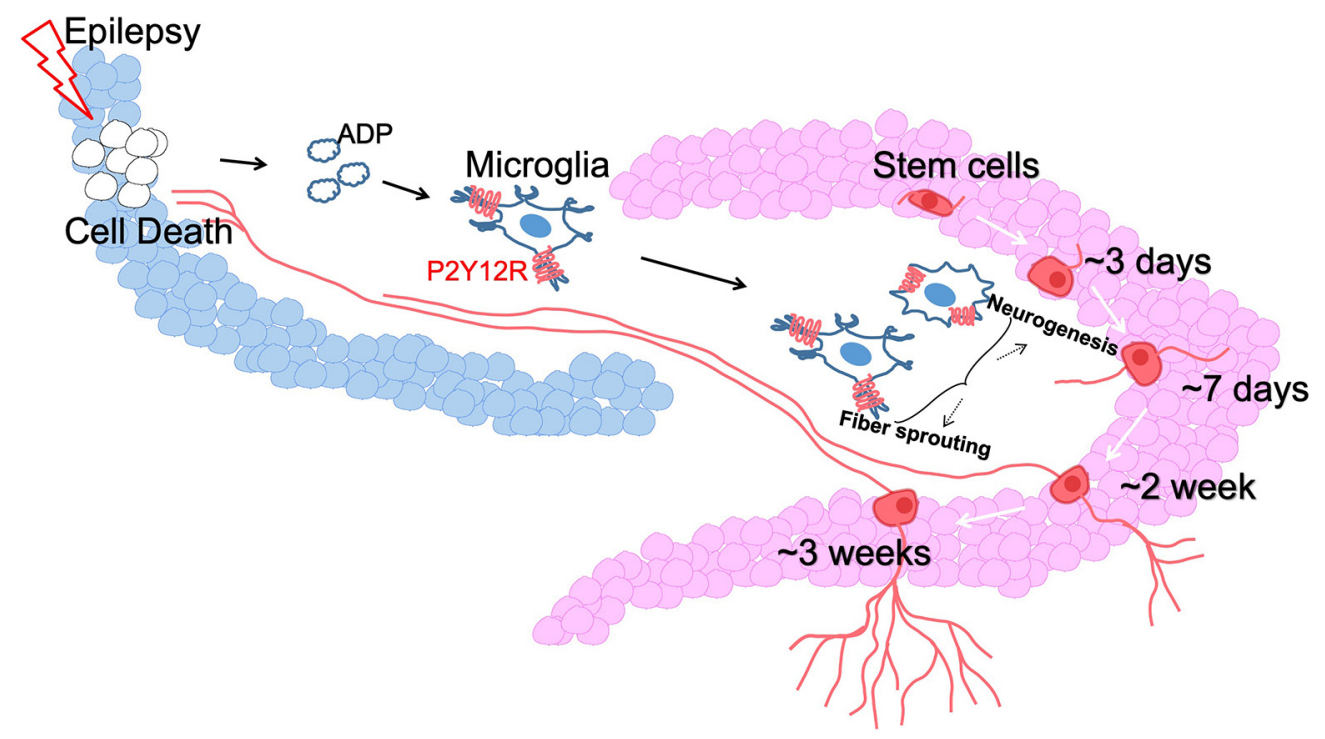

Figure 10. Model of seizure-induced microglial P2Y12R-dependent neurogenesis and immature neuronal projections. Our working model predicts that, following an initial insult (e.g., KA treatment) that leads aberrant neurogenesis and immature neuronal projections during epileptogenesis, neuronal cell death in the hippocampus triggers the release of ADP, which, acting on microglial P2Y12 receptors, promotes both KA-induced neurogenesis and sprouting as early as $3 \mathrm{~d}$ following the insult.

the brain that resulted in a reduction in seizure-induced neurogenesis as well as immature neuronal projections. Finally, both general deletion of P2Y12R and conditional deletion of P2Y12R in microglia similarly reduced seizure-induced neurogenesis and immature neuronal projections. Thus, we conclude that microglia, through their $\mathrm{P} 2 \mathrm{Y} 12 \mathrm{R}$, participate in the promotion of aberrant neurogenesis and increased neuronal projections following an initial seizure event. A limitation of our study is that, for microglial ablation and conditional P2Y12R-deletion, we used heterozygote CX3CR1 mice. Since CX3CR1 regulates basal DG neurogenesis (Rogers et al., 2011), it is likely that we have missed the full extent of neurogenesis in this context. Nevertheless, since all mice used were on this background, our comparative findings remain valid.

In our summarized model (Fig. 10), the induction of seizures by intracerebroventricular KA treatment triggers cell death that results in the release of purines, such as ATP. Released ATP and its metabolite ADP activate microglial P2Y12R, which in turn promote aberrant neurogenesis and immature neuronal projections during the latent period. Presumably, this may enhance the development of spontaneous recurrent seizures, a hallmark of epilepsy, and this will be a focus of future work. However, while we show that microglia and microglial $\mathrm{P} 2 \mathrm{Y} 12 \mathrm{R}$ regulate neurogenesis, whether these newborn neurons fully integrate into the neural circuit cannot be determined by our model since neurogenesis is transient.

\section{Roles for microglia in basal and seizure-induced neurogenesis} and immature neuronal projections

Previous investigations into microglial contributions to brain physiology suggest that microglia play a role in basal neurogenesis. First, using a similar pharmacogenetic approach to ours, it was recently shown that microglial elimination reduced steadystate neuroblast survival in the DG (Kreisel et al., 2019). Moreover, microglial activation by chronic intracerebral lipopolysaccharide (LPS) treatment was shown to impair basal DG neurogenesis that could be blocked by minocycline (a microglial activation inhibitor) treatment (Ekdahl et al., 2003; Monje et al., 2003). Furthermore, genetic disruptions of P2Y13R, which is solely localized to microglia in the brain, resulted in increased DG neurogenesis (Stefani et al., 2018), suggesting that microglia mitigate basal neurogenesis through P2Y13R. However, a genetic deficiency of CX3CR1, expressed predominantly by microglia in the brain, yielded reduced DG neurogenesis, suggesting that this signaling axis enhances basal neurogenesis (Bachstetter et al., 2011; Rogers et al., 2011; Xiao et al., 2015). These studies highlight the fact that, despite suggested contributions to basal neurogenesis by microglia, the results are conflicting and require further clarification.

In the context of seizures, neurogenesis and immature neuronal projections occur independent of one another (Sanabria Ydel et al., 2008). Although both neurogenesis and immature neuronal projections have been investigated in the literature, a greater number of studies have focused on neurogenesis. Specifically, brain inflammation induced by LPS treatment was shown to impair seizure-induced aberrant neurogenesis (Ekdahl et al., 2003). Consistent with this finding, aberrant neurogenesis in response to seizures was recently shown to be inhibited by microglial TLR9 signaling using genetic approaches (Matsuda et al., 2015). Together, these results imply that microglial activation during seizures inhibits seizure-induced neurogenesis. In seeming contrast to these findings, a different study found that seizure-induced neurogenesis was promoted by activated microglia using pharmacological approaches, including minocycline to inhibit microglia and LPS to activate microglia (Yang et al., 2010). In line with this latter finding, by pharmacological antagonism of CX3CR1 signaling, microglia are suggested to promote neuroblast production (Ali et al., 2015). Thus, the literature suggests a complex relationship between microglia and neurogenesis during both basal and seizure-induced contexts. This is understandable because some of the previous pharmacological approaches to either activate microglia using LPS treatment or inhibit microglia using minocycline are not entirely selective since neurons also respond directly to LPS treatment (Lu et al., 2014) as well as minocycline treatment (Huang et al., 2010), which could have unknown effects on other cells than microglia in the brain.

In light of these previous partially conflicting conclusions, we attempted an alternative approach with new tools to interrogate 
microglial contributions to seizure-induced neurogenesis. Recent techniques have been developed to selectively eliminate microglia from the CNS and have been used in various disease contexts (Waisman et al., 2015) but have not been applied to ascertain microglia contributions (if any) to aberrant neurogenesis following seizures. We thus adapted one such model to address this question. In addition, we used a model of seizures that reliably induces robust neurogenesis by intracerebroventricular KA delivery. Having confirmed robust induction of neurogenesis and increased immature neuronal projections (Figs. 2, 3) and efficient pharmacogenetic microglial elimination (Fig. $4 a, b$ ) following KA treatment, we assessed the degree of seizure-induced neurogenesis and neuronal sprouting. Interestingly, this approach did not alter seizure-induced neurodegeneration from the initial seizure (Fig. $4 c-e$ ). However, it consistently reduced the degree of seizure-induced neurogenesis and neuronal projections (Figs. 5, 6). However, since we used DCX immunofluorescence to quantify increased immature neuronal projections, we cannot rule out the possibility that the reduced projections observed in Figures 3 and 6 result from the maturation of the seizure-induced newborn neurons and the consequent reduction in DCX immunofluorescence. Increased immature neuronal projections induced by seizures could lead to an increase in the connectivity of neurons in the DG. Such hyperconnectivity would in turn result in dysfunctional DG neurons that are more prone to seizures.

\section{$\mathrm{P} 2 \mathrm{Y} 12$ receptors in seizures and epilepsy}

Finally, we tested for a role of P2Y12R in regulating seizureinduced aberrant neurogenesis and immature neuronal projections for the following reasons: (1) unique and exclusive basal expression of P2Y12R (Hickman et al., 2013; Zhang et al., 2014; Goldmann et al., 2016) in microglia; (2) robust transcript and protein upregulation of P2Y12R by microglia following seizures (Avignone et al., 2008; Eyo et al., 2018); (3) our previous observations that $\mathrm{P} 2 \mathrm{Y} 12 \mathrm{R}$ regulate microglial phenotypes following seizures (Eyo et al., 2014, 2017b, 2018); and (4) the availability of general P2Y12R KO mice and our newly generated conditional P2Y12R KO mice. Interestingly, our results show that genetic abrogation of mouse P2Y12R in general (Figs. 7, 8), and specifically in microglia (Fig. 9), does regulate these features of the postseizure environment. In our results, the effect of microglial ablation is more dramatic than the effect of $\mathrm{P} 2 \mathrm{Y} 12 \mathrm{R}$ elimination on seizure-induced neurogenesis, suggesting that $\mathrm{P} 2 \mathrm{Y} 12 \mathrm{R}$ is not the sole microglial protein regulating seizureinduced neurogenesis.

$\mathrm{P} 2 \mathrm{Y} 12 \mathrm{R}$ is now regarded as a marker that distinguishes microglia from other brain cells as well as other myeloid cells in the periphery (Hickman et al., 2013; Butovsky et al., 2014; Hammond et al., 2019). Emerging literature suggests that P2Y12R is essential for homeostatic brain functions, including synaptic plasticity (Sipe et al., 2016), chemotactic sensing and migration (Haynes et al., 2006; Eyo et al., 2018), vascular repair (Lou et al., 2016), and microglial-neuronal physical interactions (Eyo et al., 2014, 2015, 2017b). Moreover, P2Y12R has been implicated in the pathogenesis of several CNS diseases, including neuropathic pain (Kobayashi et al., 2008; Tozaki-Saitoh et al., 2008; Gu et al., 2016b), ischemia (Webster et al., 2013; Gelosa et al., 2014), and seizures (Eyo et al., 2014). However, whether this receptor performs detrimental (pain and ischemia) or beneficial (seizures) functions though the precise downstream mechanisms for their activity remains unclear.
Our previous study revealed that acute seizures are exacerbated in the absence of P2Y12R (Eyo et al., 2014) (also confirmed in this study in Fig. 7a) and therefore imply a hyperactivitylimiting role during seizures for the receptor. However, our current findings suggest that the receptor may also play hyperactivity-promoting roles in epileptogenesis subsequent to the initial seizure since a P2Y12R deficiency limits the extent of neurogenesis and sprouting that are thought to promote spontaneous recurring seizures. More work is needed to delineate the specific downstream mechanisms of P2Y12R activation that would induce neurogenic and sprouting phenotypes. Previous studies have shown that MAP kinase activation could be downstream of P2Y12R during neuropathic pain (Kobayashi et al., 2008). In addition, $\mathrm{P} 2 \mathrm{Y} 12 \mathrm{R}$ activation can regulate cytokine production (Charolidi et al., 2015; Liu et al., 2017), which could in turn regulate network excitability (Vezzani and Viviani, 2015) as well as neurogenesis (Na et al., 2014; Borsini et al., 2015; Kim et al., 2016). Future work will have to be directed to further understand the detailed mechanisms underlying this dual role for P2Y12R in the seizure-epilepsy continuum. Moreover, assessment of the inflammatory milieu following microglial elimination and P2Y12R depletion could also provide a better understanding of the mechanisms by which these manipulations affect neurogenesis and immature neuronal projections in our model.

In conclusion, our findings using current selective microglial targeting approaches indicate that microglia, through its P2Y12R, promote aberrant neurogenesis and increased immature neuronal projections following seizures. To our knowledge, this is the first time that microglia have been directly implicated in immature neuronal projections following seizures. Given the prevailing hypothesis that aberrant neurogenesis and sprouting following seizures are epileptogenic (Danzer, 2018), our results suggest that approaches to inhibit microglial P2Y12R function could be beneficial in limiting epileptogenesis. Drugs that block $\mathrm{P} 2 \mathrm{Y} 12 \mathrm{R}$, such as clopidogrel, are already in safe use in humans as an antiplatelet therapy for cardiovascular injury (Raju et al., 2008). Our findings indicate that such drugs, if delivered directly to the brain in epileptic patients, might ameliorate aberrant neurogenesis and potential epileptogenesis in the clinic.

\section{References}

Aimone JB, Li Y, Lee SW, Clemenson GD, Deng W, Gage FH (2014) Regulation and function of adult neurogenesis: from genes to cognition. Physiol Rev 94:991-1026.

Ali I, Chugh D, Ekdahl CT (2015) Role of fractalkine-CX3CR1 pathway in seizure-induced microglial activation, neurodegeneration, and neuroblast production in the adult rat brain. Neurobiol Dis 74:194-203.

Anacker C, Hen R (2017) Adult hippocampal neurogenesis and cognitive flexibility: linking memory and mood. Nat Rev Neurosci 18:335-346.

Andre P, Delaney SM, LaRocca T, Vincent D, DeGuzman F, Jurek M, Koller B, Phillips DR, Conley PB (2003) P2Y12 regulates platelet adhesion/activation, thrombus growth, and thrombus stability in injured arteries. J Clin Invest 112:398-406.

Avignone E, Ulmann L, Levavasseur F, Rassendren F, Audinat E (2008) Status epilepticus induces a particular microglial activation state characterized by enhanced purinergic signaling. J Neurosci 28:9133-9144.

Bachstetter AD, Morganti JM, Jernberg J, Schlunk A, Mitchell SH, Brewster KW, Hudson CE, Cole MJ, Harrison JK, Bickford PC, Gemma C (2011) Fractalkine and CX 3 CR1 regulate hippocampal neurogenesis in adult and aged rats. Neurobiol Aging 32:2030-2044.

Bausch SB, McNamara JO (2004) Contributions of mossy fiber and CA1 pyramidal cell sprouting to dentate granule cell hyperexcitability in kainic acid-treated hippocampal slice cultures. J Neurophysiol 92:3582-3595.

Beggs S, Salter MW (2013) The known knowns of microglia-neuronal signalling in neuropathic pain. Neurosci Lett 557:37-42.

Bennett ML, Bennett FC, Liddelow SA, Ajami B, Zamanian JL, Fernhoff NB, 
Mulinyawe SB, Bohlen CJ, Adil A, Tucker A, Weissman IL, Chang EF, Li G, Grant GA, Hayden Gephart MG, Barres BA (2016) New tools for studying microglia in the mouse and human CNS. Proc Natl Acad Sci U S A 113:E1738-E1746.

Borsini A, Zunszain PA, Thuret S, Pariante CM (2015) The role of inflammatory cytokines as key modulators of neurogenesis. Trends Neurosci 38:145-157.

Butovsky O, Jedrychowski MP, Moore CS, Cialic R, Lanser AJ, Gabriely G, Koeglsperger T, Dake B, Wu PM, Doykan CE, Fanek Z, Liu L, Chen Z, Rothstein JD, Ransohoff RM, Gygi SP, Antel JP, Weiner HL (2014) Identification of a unique TGF-beta-dependent molecular and functional signature in microglia. Nat Neurosci 17:131-143.

Charolidi N, Schilling T, Eder C (2015) Microglial Kv1.3 channels and P2Y12 receptors differentially regulate cytokine and chemokine release from brain slices of young adult and aged mice. PLoS One 10:e128463.

Cho KO, Lybrand ZR, Ito N, Brulet R, Tafacory F, Zhang L, Good L, Ure K, Kernie SG, Birnbaum SG, Scharfman HE, Eisch AJ, Hsieh J (2015) Aberrant hippocampal neurogenesis contributes to epilepsy and associated cognitive decline. Nat Commun 6:6606.

Cronk JC, Filiano AJ, Louveau A, Marin I, Marsh R, Ji E, Goldman DH, Smirnov I, Geraci N, Acton S, Overall CC, Kipnis J (2018) Peripherally derived macrophages can engraft the brain independent of irradiation and maintain an identity distinct from microglia. J Exp Med 215:16271647.

Danzer SC (2018) Contributions of adult-generated granule cells to hippocampal pathology in temporal lobe epilepsy: a neuronal bestiary. Brain Plast 3:169-181.

Devinsky O, Vezzani A, Najjar S, De Lanerolle NC, Rogawski MA (2013) Glia and epilepsy: excitability and inflammation. Trends Neurosci 36: 174-184.

Ekdahl CT, Claasen JH, Bonde S, Kokaia Z, Lindvall O (2003) Inflammation is detrimental for neurogenesis in adult brain. Proc Natl Acad Sci U S A 100:13632-13637.

Eyo UB, Wu LJ (2013) Bi-directional microglia-neuron communication in the healthy brain. Neural Plast 2013:456857.

Eyo UB, Peng J, Swiatkowski P, Mukherjee A, Bispo A, Wu LJ (2014) Neuronal hyperactivity recruits microglial processes via neuronal NMDA receptors and microglial P2Y12 receptors after status epilepticus. J Neurosci 34:10528-10540.

Eyo UB, Gu N, De S, Dong H, Richardson JR, Wu LJ (2015) Modulation of microglial process convergence toward neuronal dendrites by extracellular calcium. J Neurosci 35:2417-2422.

Eyo UB, Murugan M, Wu LJ (2017a) Microglia-neuron communication in epilepsy. Glia 65:5-18.

Eyo UB, Peng J, Murugan M, Mo M, Lalani A, Xie P, Xu P, Margolis DJ, Wu LJ (2017b) Regulation of physical microglia-neuron interactions by fractalkine signaling after status epilepticus. eNeuro 3:ENEURO.020916.2016.

Eyo UB, Mo M, Yi MH, Murugan M, Liu J, Yarlagadda R, Margolis DJ, Xu P, Wu LJ (2018) P2Y12R-dependent translocation mechanisms gate the changing microglial landscape. Cell Rep 23:959-966.

Gelosa P, Lecca D, Fumagalli M, Wypych D, Pignieri A, Cimino M, Verderio C, Enerbäck M, Nikookhesal E, Tremoli E, Abbracchio MP, Sironi L (2014) Microglia is a key player in the reduction of stroke damage promoted by the new antithrombotic agent ticagrelor. J Cereb Blood Flow Metab 34:979-988.

Godale CM, Danzer SC (2018) Signaling pathways and cellular mechanisms regulating mossy fiber sprouting in the development of epilepsy. Front Neurol 9:298.

Goldmann T, Wieghofer P, Jordão MJ, Prutek F, Hagemeyer N, Frenzel K, Amann L, Staszewski O, Kierdorf K, Krueger M, Locatelli G, Hochgerner H, Zeiser R, Epelman S, Geissmann F, Priller J, Rossi FM, Bechmann I, Kerschensteiner M, Linnarsson S, et al. (2016) Origin, fate and dynamics of macrophages at central nervous system interfaces. Nat Immunol 17:797-805.

Gonçalves JT, Schafer ST, Gage FH (2016) Adult neurogenesis in the hippocampus: from stem cells to behavior. Cell 167:897-914.

Gray WP, May K, Sundström LE (2002) Seizure induced dentate neurogenesis does not diminish with age in rats. Neurosci Lett 330:235-238.

Gu N, Eyo UB, Murugan M, Peng J, Matta S, Dong H, Wu LJ (2016a) Microglial P2Y12 receptors regulate microglial activation and surveillance during neuropathic pain. Brain Behav Immun 55:82-92.
Gu N, Peng J, Murugan M, Wang X, Eyo UB, Sun D, Ren Y, DiCicco-Bloom E, Young W, Dong H, Wu LJ (2016b) Spinal microgliosis due to resident microglial proliferation is required for pain hypersensitivity after peripheral nerve injury. Cell Rep 16:605-614.

Hammond TR, Robinton D, Stevens B (2018) Microglia and the brain: complementary partners in development and disease. Annu Rev Cell Dev Biol 34:523-544.

Hammond TR, Dufort C, Dissing-Olesen L, Giera S, Young A, Wysoker A, Walker AJ, Gergits F, Segel M, Nemesh J, Marsh SE, Saunders A, Macosko E, Ginhoux F, Chen J, Franklin RJ, Piao X, McCarroll SA, Stevens B (2019) Single-cell RNA sequencing of microglia throughout the mouse lifespan and in the injured brain reveals complex cell-state changes. Immunity 50:253-271.e6.

Häussler U, Rinas K, Kilias A, Egert U, Haas CA (2016) Mossy fiber sprouting and pyramidal cell dispersion in the hippocampal CA2 region in a mouse model of temporal lobe epilepsy. Hippocampus 26:577-588.

Haynes SE, Hollopeter G, Yang G, Kurpius D, Dailey ME, Gan WB, Julius D (2006) The P2Y12 receptor regulates microglial activation by extracellular nucleotides. Nat Neurosci 9:1512-1519.

Hickman SE, Kingery ND, Ohsumi TK, Borowsky ML, Wang LC, Means TK, El Khoury J (2013) The microglial sensome revealed by direct RNA sequencing. Nat Neurosci 16:1896-1905.

Hosford BE, Liska JP, Danzer SC (2016) Ablation of newly generated hippocampal granule cells has disease-modifying effects in epilepsy. J Neurosci 36:11013-11023.

Huang WC, Qiao Y, Xu L, Kacimi R, Sun X, Giffard RG, Yenari MA (2010) Direct protection of cultured neurons from ischemia-like injury by minocycline. Anat Cell Biol 43:325-331.

Jessberger S, Parent JM (2015) Epilepsy and adult neurogenesis. Cold Spring Harb Perspect Biol 7:a020677.

Journiac N, Doulazmi M, Pajak F, Mariani J, Vernet-der Garabedian B (2005) Quantitative analysis of microglial cells in the degenerating cerebellum of the staggerer (RORA $(\mathrm{sg} / \mathrm{sg}))$ mutant mouse. J Neurogenet 19: 143-154.

Jung S, Aliberti J, Graemmel P, Sunshine MJ, Kreutzberg GW, Sher A, Littman DR (2000) Analysis of fractalkine receptor CX(3)CR1 function by targeted deletion and green fluorescent protein reporter gene insertion. Mol Cell Biol 20:4106-4114

Karve IP, Taylor JM, Crack PJ (2016) The contribution of astrocytes and microglia to traumatic brain injury. Br J Pharmacol 173:692-702.

Kim YK, Na KS, Myint AM, Leonard BE (2016) The role of proinflammatory cytokines in neuroinflammation, neurogenesis and the neuroendocrine system in major depression. Prog Neuropsychopharmacol Biol Psychiatry 64:277-284.

Kobayashi K, Yamanaka H, Fukuoka T, Dai Y, Obata K, Noguchi K (2008) $\mathrm{P} 2 \mathrm{Y} 12$ receptor upregulation in activated microglia is a gateway of $\mathrm{p} 38$ signaling and neuropathic pain. J Neurosci 28:2892-2902.

Kreisel T, Wolf B, Keshet E, Licht T (2019) Unique role for dentate gyrus microglia in neuroblast survival and in VEGF-induced activation. Glia 67:594-618.

Lévesque M, Avoli M, Bernard C (2016) Animal models of temporal lobe epilepsy following systemic chemoconvulsant administration. J Neurosci Methods 260:45-52.

Liu M, Yao M, Wang H, Xu L, Zheng Y, Huang B, Ni H, Xu S, Zhou X, Lian Q (2017) P2Y12 receptor-mediated activation of spinal microglia and p38MAPK pathway contribute to cancer-induced bone pain. J Pain Res 10:417-426.

Lou N, Takano T, Pei Y, Xavier AL, Goldman SA, Nedergaard M (2016) Purinergic receptor P2RY12-dependent microglial closure of the injured blood-brain barrier. Proc Natl Acad Sci U S A 113:1074-1079.

Lu Y, Peng F, Dong M, Yang H (2014) Endocannabinoid 2-arachidonylglycerol protects primary cultured neurons against LPS-induced impairments in rat caudate nucleus. J Mol Neurosci 54:49-58.

Ma Y, Wang J, Wang Y, Yang GY (2017) The biphasic function of microglia in ischemic stroke. Prog Neurobiol 157:247-272.

Matsuda T, Murao N, Katano Y, Juliandi B, Kohyama J, Akira S, Kawai T, Nakashima K (2015) TLR9 signalling in microglia attenuates seizureinduced aberrant neurogenesis in the adult hippocampus. Nat Commun 6:6514.

Mirrione MM, Konomos DK, Gravanis I, Dewey SL, Aguzzi A, Heppner FL, Tsirka SE (2010) Microglial ablation and lipopolysaccharide precondi- 
tioning affects pilocarpine-induced seizures in mice. Neurobiol Dis 39:85-97.

Monje ML, Toda H, Palmer TD (2003) Inflammatory blockade restores adult hippocampal neurogenesis. Science 302:1760-1765.

Na KS, Jung HY, Kim YK (2014) The role of pro-inflammatory cytokines in the neuroinflammation and neurogenesis of schizophrenia. Prog Neuropsychopharmacol Biol Psychiatry 48:277-286.

Nayak D, Roth TL, McGavern DB (2014) Microglia development and function. Annu Rev Immunol 32:367-402.

Parent JM (2007) Adult neurogenesis in the intact and epileptic dentate gyrus. Prog Brain Res 163:529-540.

Parent JM, Murphy GG (2008) Mechanisms and functional significance of aberrant seizure-induced hippocampal neurogenesis. Epilepsia 49 [Suppl 5]:19-25.

Parent JM, Yu TW, Leibowitz RT, Geschwind DH, Sloviter RS, Lowenstein DH (1997) Dentate granule cell neurogenesis is increased by seizures and contributes to aberrant network reorganization in the adult rat hippocampus. J Neurosci 17:3727-3738.

Parkhurst CN, Yang G, Ninan I, Savas JN, Yates JR 3rd, Lafaille JJ, Hempstead BL, Littman DR, Gan WB (2013) Microglia promote learningdependent synapse formation through brain-derived neurotrophic factor. Cell 155:1596-1609.

Peng J, Gu N, Zhou L, Eyo UB, Murugan M, Gan WB, Wu LJ (2016) Microglia and monocytes synergistically promote the transition from acute to chronic pain after nerve injury. Nat Commun 7:12029.

Peng J, Liu Y, Umpierre AD, Xie M, Tian DS, Richardson JR, Wu LJ (2019) Microglial P2Y12 receptor regulates ventral hippocampal CA1 neuronal excitability and innate fear in mice. Mol Brain 12:71.

Racine RJ (1972) Modification of seizure activity by electrical stimulation: II. Motor seizure. Electroencephalogr Clin Neurophysiol 32:281-294.

Raju NC, Eikelboom JW, Hirsh J (2008) Platelet ADP-receptor antagonists for cardiovascular disease: past, present and future. Nat Clin Pract Cardiovasc Med 5:766-780.

Rogers JT, Morganti JM, Bachstetter AD, Hudson CE, Peters MM, Grimmig BA, Weeber EJ, Bickford PC, Gemma C (2011) CX3CR1 deficiency leads to impairment of hippocampal cognitive function and synaptic plasticity. J Neurosci 31:16241-16250.

Römer B, Krebs J, Overall RW, Fabel K, Babu H, Overstreet-Wadiche L, Brandt MD, Williams RW, Jessberger S, Kempermann G (2011) Adult hippocampal neurogenesis and plasticity in the infrapyramidal bundle of the mossy fiber projection: I. Co-regulation by activity. Front Neurosci 5:107.

Salter MW, Beggs S (2014) Sublime microglia: expanding roles for the guardians of the CNS. Cell 158:15-24.

Sanabria Ydel C, Argañaraz GA, Lima E, Priel MR, Trindade Eda S, Loeb LM, Scorza FA, Cavalheiro EA, Amado D, Naffah-Mazzacoratti Mda G (2008) Neurogenesis induced by seizures in the dentate gyrus is not related to mossy fiber sprouting but is age dependent in developing rats. Arq Neuropsiquiatr 66:853-860.
Sarlus H, Heneka MT (2017) Microglia in Alzheimer's disease. J Clin Invest 127:3240-3249.

Sierra A, Martín-Suárez S, Valcárcel-Martín R, Pascual-Brazo J, Aelvoet SA, Abiega O, Deudero JJ, Brewster AL, Bernales I, Anderson AE, Baekelandt V, Maletić-Savatić M, Encinas JM (2015) Neuronal hyperactivity accelerates depletion of neural stem cells and impairs hippocampal neurogenesis. Cell Stem Cell 16:488-503.

Sipe GO, Lowery RL, Tremblay ME, Kelly EA, Lamantia CE, Majewska AK (2016) Microglial P2Y12 is necessary for synaptic plasticity in mouse visual cortex. Nat Commun 7:10905.

Stefani J, Tschesnokowa O, Parrilla M, Robaye B, Boeynaems JM, AckerPalmer A, Zimmermann H, Gampe K (2018) Disruption of the microglial ADP receptor P2Y13 enhances adult hippocampal neurogenesis. Front Cell Neurosci 12:134.

Tozaki-Saitoh H, Tsuda M, Miyata H, Ueda K, Kohsaka S, Inoue K (2008) $\mathrm{P} 2 \mathrm{Y} 12$ receptors in spinal microglia are required for neuropathic pain after peripheral nerve injury. J Neurosci 28:4949-4956.

Vezzani A (2014) Epilepsy and inflammation in the brain: overview and pathophysiology. Epilepsy Curr 14:3-7.

Vezzani A, Viviani B (2015) Neuromodulatory properties of inflammatory cytokines and their impact on neuronal excitability. Neuropharmacology 96:70-82.

Waisman A, Ginhoux F, Greter M, Bruttger J (2015) Homeostasis of microglia in the adult brain: review of novel microglia depletion systems. Trends Immunol 36:625-636.

Waltl I, Käufer C, Gerhauser I, Chhatbar C, Ghita L, Kalinke U, Löscher W (2018) Microglia have a protective role in viral encephalitis-induced seizure development and hippocampal damage. Brain Behav Immun 74:186-204.

Webster CM, Hokari M, McManus A, Tang XN, Ma H, Kacimi R, Yenari MA (2013) Microglial P2Y12 deficiency/inhibition protects against brain ischemia. PLoS One 8:e70927.

Wirenfeldt M, Dalmau I, Finsen B (2003) Estimation of absolute microglial cell numbers in mouse fascia dentata using unbiased and efficient stereological cell counting principles. Glia 44:129-139.

Xiao F, Xu JM, Jiang XH (2015) CX3 chemokine receptor 1 deficiency leads to reduced dendritic complexity and delayed maturation of newborn neurons in the adult mouse hippocampus. Neural Regen Res 10:772-777.

Yang F, Liu ZR, Chen J, Zhang SJ, Quan QY, Huang YG, Jiang W (2010) Roles of astrocytes and microglia in seizure-induced aberrant neurogenesis in the hippocampus of adult rats. J Neurosci Res 88:519-529.

Younger D, Murugan M, Rama Rao KV, Wu LJ, Chandra N (2019) Microglia receptors in animal models of traumatic brain injury. Mol Neurobiol 56:5202-5228.

Zhang Y, Chen K, Sloan SA, Bennett ML, Scholze AR, O'Keeffe S, Phatnani HP, Guarnieri P, Caneda C, Ruderisch N, Deng S, Liddelow SA, Zhang C, Daneman R, Maniatis T, Barres BA, Wu JQ (2014) An RNA-sequencing transcriptome and splicing database of glia, neurons, and vascular cells of the cerebral cortex. J Neurosci 34:11929-11947. 